\title{
La valoración social del multiculturalismo y del monoculturalismo en Europa
}

\author{
Eduardo Bericat Alastuey \\ Universidad de Sevilla. Departamento de Sociología \\ ebericat@us.es
}

Recibido: 17-04-2007

Aceptado: 25-06-2008

\section{Resumen}

Partiendo de la tesis sostenida por Verena Stolcke, que advierte de la existencia de un cambio en el discurso mediante el que las poblaciones autóctonas rechazan a los inmigrantes, se ha realizado una investigación empírica con el objeto de verificar si, en efecto, los discursos basados en un fundamentalismo cultural están sustituyendo a los explícitamente racistas o xenófobos. El fundamentalismo cultural alerta del peligro que supone la entrada masiva de inmigrantes para la homogeneidad y la integridad cultural de la nación. Mediante análisis multivariables realizados con datos de la European Social Survey, se ha elaborado una tipología de europeos según su grado de monoculturalismo (valoración de la homogeneidad cultural), o su grado de multiculturalismo (valoración de la diversidad cultural). En esta tipología, también puede distinguirse entre aquellos europeos que defienden el monoculturalismo o el multiculturalismo por razones pragmáticas, y aquéllos otros que argumentan desde una concepción esencialista de la cultura. Tomando como base la clasificación en cuatro tipos, se determina el posicionamiento de cada uno de los países europeos, así como las correlaciones existentes entre el grado de monoculturalismo y tres importantes variables de identificación sociocultural: nivel educativo, posicionamiento ideológico y grado de religiosidad.

Palabras clave: multiculturalidad, valores sociales, cohesión social, cohesión cultural, cultura, inmigración, racismo, xenofobia, discriminación, minorías.

\section{Abstract. The social valuation of multiculturalism and monoculturalism in Europe}

Following Verena Stolcke's thesis, which defends that a change on the discourse through which native population rejects immigrants, an empirical research has been carried out attempting to verify if the discourses based on cultural fundamentalism are replacing those explicitly racist or xenophobic. Cultural fundamentalism warns against the risk that massive immigration implies for the homogeneity and cultural integrity of the nation. A new typology of Europeans based on their monoculturalism (valuation of cultural homogeneity) or their multiculturalism rate (valuation of cultural diversity) has been created through multivariable analysis using data from the European Social Survey. This typology also allows for a distinction between those

* Este trabajo forma parte de una investigación titulada Identidad y fragmentación moral en Europa: religión, valores sociales y conflicto cultural, financiada por la Fundación Centro de Estudios Andaluces y por la Fundación BBVA, al obtener una de la Ayudas a la Investigación en Ciencias Sociales de la Tercera Convocatoria. 
Europeans who defend monoculturalism for pragmatic reasons and those who argue from an essentialist conception of culture. Considering a classification into four types, the orientation of each of the European countries has been determined, as well as the existing correlation between the degree of monoculturalism and three important variables for socio-cultural identification: education level, ideological orientation and religiosity.

Key words: multiculturality, social values, social cohesion, cultural cohesion, culture, immigration, racism, xenophobia, discrimination, minorities.

\section{Sumario}

\section{Cultura e inmigracón}

2. Opiniones valorativas en torno a la uniformidad y a la diversidad cultural

3. El monoculturalismo y el multiculturalismo

4. La estructura básica del debate acerca del multiculturalismo
5. Posicionamiento ideológico y multiculturalismo

6. El multiculturalismo como respuesta moral al reto de la multiculturalidad

Bibliografía

\section{Cultura e inmigración}

Europa se ha convertido en una sociedad multiétnica y multicultural. Incluso en España, un país de inmigración reciente, y según el Observatorio Permanente de la Inmigración, se contabilizaron, a día 31 de marzo de 2008, un total de 4.192.835 extranjeros con certificado de registro o tarjeta de residencia. La procedencia de estos extranjeros es muy diversa: 1.658 .468 proceden de la Europa comunitaria; 119.582 , del resto de Europa; 873.998, de África; 1.269.053, de Iberoamérica; 19.328, de América del Norte; 249.643, de Asia, y 11.632, de Oceanía. Así pues, extranjeros de los cinco continentes, procedentes de muchos países, habitan nuestras ciudades y pueblos, aportando una diversidad cultural hasta hace poco impensable. Todos ellos, al desplazarse físicamente, llegan con su cultura portando lenguas, religiones, modos de vida, visiones del mundo, valores sociales, costumbres y tradiciones que se distinguen, en mayor o menor medida, de las pautas culturales vigentes en la sociedad receptora. A partir de ese momento, la homogeneidad étnica y cultural puede convertirse en un objeto del deseo, pero, en cualquier caso, ha dejado de ser una realidad.

El extranjero que llega se enfrenta a la dificultad de vivir en un medio cultural que le es extraño, se enfrenta al riesgo de experimentar un cierto grado de alienación vital. También se enfrenta a otros muchos riesgos: a la soledad, al desempleo, a la nostalgia, a la explotación en el mercado de trabajo, al sacrificio, a la carencia de derechos sociales, al trabajo duro o a la falta de vivienda. Y puede que haya de enfrentarse, además, al simple y atávico recelo de quienes ven en el «otro diferente» un peligro para la integridad y para la identidad cultural de la sociedad receptora. El rechazo al extranjero inmigrante puede estar alimentado por múltiples conflictos de intereses, sean percibidos o 
reales. La población autóctona puede pensar que los inmigrantes quitan puestos de trabajo a los nacionales, que absorben gran parte de las prestaciones sociales disponibles, que incrementan las tasas de criminalidad, que reducen el nivel de los salarios o que elevan el precio de la vivienda. Pero lo que podemos observar cada día es que, en muchos casos, este rechazo se basa exclusivamente en razones culturales.

El rechazo a los inmigrantes fundado en razones culturales puede adquirir formas muy diversas. Típicamente, se expresa en un fundamentalismo ideológico que valora en grado sumo la homogeneidad cultural de la sociedad receptora. Los fundamentalistas culturales creen que una entrada masiva de inmigrantes pondría en peligro la «homogeneidad de la nación», así como la esencia de su «cultura» y de sus "valores» esenciales. La ruptura de la integridad cultural del país, de su modo de vida, sus tradiciones, su lengua y sus costumbres, resquebrajaría la cohesión cultural y social, descomponiendo el consenso nacional considerado imprescindible para el mantenimiento del orden y de la paz social. La fragmentación social y moral de los países abriría la puerta a múltiples frentes de conflicto culturales e identitarios.

Atendiendo al creciente fundamentalismo cultural que se observa en las sociedades europeas, Verena Stolcke sostiene la tesis de que se ha producido un cambio en el discurso mediante el que la población autóctona rechaza a los inmigrantes. Este rechazo, que ha dejado de expresarse en términos explícitamente racistas o xenófobos, se expresa hoy poniendo de relieve el peligro que supone la entrada masiva de inmigrantes para la homogeneidad e integridad cultural de la nación (Stolcke, 1995). En el ámbito europeo, la necesidad de construir una idea de Europa basada en las raíces de una cultura europea común (Amin, 2004), capaz de otorgar una identidad colectiva que trascienda la procurada por las diversas naciones europeas, intensifica aún más este deseo de uniformidad cultural.

La intensa valoración de la uniformidad cultural en el interior de los países, a la que podemos denominar monoculturalismo, no sólo afecta a los inmigrantes por cuanto son «seres de cultura» diferentes, es decir, "otros» que la población autóctona puede percibir como un excluyente «ellos» ante un «nosotros» incluyente, sino que también les afecta en la medida de que tales inmigrantes conforman minorías en la estructura social de las sociedades receptoras. Su condición de minoría diferenciada culturalmente no sólo les expone al riesgo de la discriminación y de la exclusión, sino también a la falta del adecuado respeto interindividual y del adecuado reconocimiento colectivo. Cuando esto sucede, sobre todo cuando la explotación y la humillación se dan la mano, las minorías reaccionan potenciando sus vínculos comunitarios y sus símbolos identitarios. Es entonces cuando la fragmentación social y moral de la sociedad aumenta, y cuando comienzan a aparecer intensos conflictos culturales, expresivamente simbólicos, bajo los que también subyacen justificables lógicas de defensa del propio interés. Es entonces cuando las minorías culturales intensifican el grado de monoculturalismo interno como forma de resistencia y oposición al intenso monoculturalismo existente en el entorno. Los conti- 
nuos y graves conflictos culturales que emergen por toda Europa, bien conocidos por todos, expresan las contradicciones de una compleja dialéctica, material y simbólica, entre un "NOSOTROS/ellos» excluyente y entre una «MAYORÍA/minoría» dominante.

En esta situación de tensiones prácticamente irreductibles, tan perniciosas para la dignidad y para las condiciones de vida de los inmigrantes, como para el logro de un modelo de cohesión social y cultural que tenga en cuenta la diversidad, es decir, la multiculturalidad de hecho presente en las sociedades europeas, no ha de extrañarnos que el multiculturalismo normativo ocupe un lugar privilegiado en el núcleo mismo del gran debate existente en torno a un nuevo modelo de sociedad capaz de articular la justicia en unas sociedades cada vez más fragmentadas moral y socialmente, cultural e identitariamente.

El trabajo que presentamos en este artículo aborda, pues, un sólo aspecto de la relación entre "cultura e inmigración», si bien creemos que, a tenor de lo dicho, constituye un aspecto clave para la población inmigrante, para las sociedades receptoras y también para el destino común de Europa y de los europeos.

En el marco de este complejo mundo de fenómenos sociales y culturales, nuestro trabajo se ha centrado en estimar con suficiente rigor científico, utilizando datos de la European Social Survey realizada en el año 2002, la medida en que la población europea se adscribe, bien a valores sociales monoculturales, o de defensa de la uniformidad cultural en el seno de los países, bien a valores multiculturales, o de defensa de la diversidad cultural. En primer término, nuestra estrategia analítica ha consistido en localizar aquellas preguntas cuyo contenido semántico estuviera relacionado con la valoración de la homogeneidad o la heterogeneidad cultural del país. En segundo término, mediante la aplicación de un análisis de componentes principales categóricos, hemos obtenido, con todas esas variables, una dimensión de valor que corresponde al grado de monoculturalismo o de multiculturalismo al que se adscribe cada uno de los europeos entrevistados. En este mismo análisis multivariable también hemos obtenido una segunda dimensión que distingue dos tipos de monoculturalismo y de multiculturalismo. Estos dos tipos están relacionados con dos concepciones diferentes de cultura, una esencialista y otra pragmatista. La concepción esencialista se corresponde con la idea de cultura tal y como aparece en la obra de Herder y en la tradición del romanticismo alemán, mientras que la concepción pragmatista está vinculada a la obra de Montesquieu y a la herencia intelectual de la Ilustración francesa.

El descubrimiento de esta segunda dimensión nos ha permitido elaborar una tipología de adscripción valorativa en torno a la diversidad cultural que va más allá de la mera consideración del grado cuantitativo de monoculturalismo o de multiculturalismo. Así, mediante el cruce de ambas dimensiones, hemos descubierto la existencia de cuatro posicionamientos culturales básicos: monoculturalismo esencialista, monoculturalismo pragmático, multiculturalismo pragmático y multiculturalismo esencialista. La mayor parte de los debates públicos en torno a esta cuestión fundamental se dirimen en el sentido de definir, mono- 
tónicamente, la propia posición en términos de mayor o menor multiculturalismo. Sin embargo, esta simple consideración monotónica no refleja adecuadamente la estructura básica de posiciones ideológico-morales presentes en la opinión pública o en los discursos de los europeos. El posicionamiento moral de las personas ante el fenómeno de la diversidad social y cultural es bastante complejo, paradójico y contradictorio, y esto es lo que explica el hecho de que, tras un debate aparentemente simple y libre de fuertes compromisos morales ("defender o no la diversidad cultural»), se esconda una profunda complejidad ética, social y política, un laberinto de cuya resolución depende en parte el futuro moral de Europa.

\section{Opiniones valorativas en torno a la uniformidad} y a la diversidad cultural

Del amplio cuestionario utilizado en la Encuesta Social Europea, 2002, hemos seleccionado diez preguntas cuyo contenido informativo está relacionado, directa o indirectamente, con la valoración expresada por los europeos respecto a la uniformidad o a la diversidad cultural de sus respectivos países. En las cuatro primeras, podemos comprobar la importancia otorgada a algunos rasgos culturales en tanto criterios a tener en cuenta a la hora de permitir o no la entrada de inmigrantes (cuadro 1.a). En un segundo bloque, compuesto de tres preguntas, podemos observar en qué medida los europeos consideramos si es mejor para un país que casi todo el mundo comparta al menos una lengua común, las mismas costumbres y tradiciones y la misma religión (cuadro 1.b). En este mismo cuadro, también se incluyen los resultados de la pregunta acerca de si la entrada de personas procedentes de otros países enriquece o empobrece la vida cultural del país. Por último, hemos incluido en el siguiente cuadro las respuestas a dos preguntas complementarias sobre política inmigratoria que contienen un profundo trasfondo cultural (cuadro 1.c). En ambas, se solicita el grado de acuerdo o desacuerdo con sendas frases: $a$ ) «Si un país quiere evitar problemas, debe poner fin a la inmigración», y $b$ ) «Las distintas comunidades de personas que han venido a vivir [al país] deberían poder educar a sus hijos en escuelas separadas, si así lo desean».

Con un simple análisis de las distribuciones de frecuencias de cada una de estas diez variables, pueden obtenerse ya algunas conclusiones fundamentales acerca del grado de valoración que los europeos otorgan a los diversos tipos de homogeneidad cultural en el seno de los países. Con respecto a cada uno de los tipos, consideramos importante determinar, tanto los niveles de consenso o de disenso presentes en la opinión pública europea, como sus grados de polarización. Para determinar la existencia de un consenso o de un disenso, utilizaremos el Indicador de Opinión Pública (IOP), que refleja el balance de respuestas contabilizando solamente aquellos entrevistados que han expresado una opinión definida. Esto es, los porcentajes se recalculan excluyendo a los individuos que bien hayan expresado alguna posición neutral, indecisa o indiferente, o bien hayan manifestado no saber o no hayan contestado. Para determinar la existencia de 
Cuadro 1.a. Cohesión cultural: criterios de entrada de inmigrantes

\begin{tabular}{lrrrrrr}
\hline & \multicolumn{5}{c}{ Importancia } \\
\cline { 2 - 7 } & Nada & & \multicolumn{3}{c}{ Mucha } \\
\cline { 2 - 7 } Criterios & $(\mathbf{0 - 1 - 2 )}$ & $(3-4)$ & $(5)$ & $(6-7)$ & $(8-9-10)$ & Ns/Nc \\
\hline $\begin{array}{l}\text { Hablar la lengua } \\
\text { del país de acogida }\end{array}$ & 9,4 & 7,8 & 11,0 & 20,2 & 50,4 & 1,4 \\
$\begin{array}{l}\text { Proceder de un país } \\
\text { cristiano }\end{array}$ & 43,6 & 13,5 & 14,3 & 12,0 & 14,2 & 2,4 \\
$\begin{array}{c}\text { Adoptar el modo de vida } \\
\text { del país de acogida }\end{array}$ & 5,6 & 5,0 & 9,5 & 19,3 & 59,0 & 1,6 \\
Ser de raza blanca & 61,5 & 11,3 & 11,0 & 6,7 & 7,4 & 2,1 \\
\hline
\end{tabular}

Fuente: ESS, 2002. Elaboración propia.

polarización, utilizaremos el Indicador de Polarización de la Opinión Pública (IPOP), que se calcula poniendo en relación el total de respuestas que han optado por señalar posiciones extremas, con el total de respuestas que han elegido posiciones moderadas o centrales de cada una de las escalas ${ }^{1}$.

Los datos contenidos en el cuadro 1.a indican con toda claridad que los europeos otorgan suma importancia al hecho de que los inmigrantes sean capaces de hablar la lengua del país receptor, así como que estén dispuestos a adoptar el modo de vida de los habitantes de ese mismo país. Sin embargo, la importancia que conceden al hecho de proceder de un país de tradición cristiana, o al hecho de ser de raza blanca es muchísimo menor. En suma, los europeos valoramos en altísimo grado tanto la homogeneidad lingüistica como la uniformidad en el modo de vida de los habitantes de cada país. La valoración de la uniformidad lingüística alcanza la cota de un gran consenso de la opinión pública europea $(\mathrm{IOP}=80,4 \%)$, pero aún es mayor la cota de consenso alcanzada por la uniformidad de modo de vida (IOP = 88,1\%). Según los datos del cuadro, el grado de polarización existente en ambas variables es muy alto, ya que tanto en el caso de la lengua $(50,4 \%)$, como en el caso del modo de vida $(59,0 \%)$, más de la mitad de la población ha optado por valores extremos de la escala, es decir, ha señalado la gran importancia que otorgaría a hablar la misma lengua y a comprometerse con el modo de vida como criterio de entrada de inmigrantes. Así, la preocupación que sienten los europeos por el efecto que la inmigración pueda tener sobre la cohesión cultural de su país parece bastante evidente. De la misma manera, es evidente que estos datos, es decir, estos dos grandes consensos y su alta polarización, explican la intensa presión «asimilacionista» que pueden sentir los inmigrantes a la hora de hablar la misma lengua y de adaptarse al mismo modo de vida.

1. Una explicación más detallada de ambos indicadores puede verse en E. Bericat (dir.) (2003), El conflicto cultural en España: Acuerdos y desacuerdos entre los españoles, Madrid, CIS. 
El bajo índice obtenido por el criterio de proceder de un país de tradición cristiana (IOP $=31,5 \%$ ), nos habla de la existencia de consenso europeo a la hora de considerar la reducida importancia del criterio religioso. El índice todavía inferior alcanzado por el hecho de ser de raza blanca $(\mathrm{IOP}=15,9 \%)$ señala la existencia de un gran consenso a la hora de determinar la poca importancia de este criterio. El contraste entre, por un lado, los tres criterios culturales (lengua, modo de vida y tradición religiosa) y, por otro, el criterio de la raza, avalaría la tesis de Stolcke en el sentido de que el discurso de la discriminación ha dejado de ser explícitamente racista o xenófobo, y se está conformando como un discurso puramente cultural. Lo cierto es, sin embargo, que algunos análisis que hemos realizado con datos de esta misma encuesta revelan que un $22 \%$ de la población europea expresa una clara discriminación étnico-racista a la hora de limitar la entrada de inmigrantes. Datos incontestables que en modo alguno avalan la tesis de que el discurso racista en Europa es un discurso público superado, dormido o reprimido.

Tomando como referencia el segundo bloque de opiniones valorativas (cuadro 1.b), cuyas preguntas de origen no hacen referencia explícita al fenómeno de la inmigración, sino directamente al de la homogeneidad cultural del país, podemos observar que la valoración de la uniformidad, salvo en el ámbito cultural de la religión, sigue predominando sobre la de la diversidad. En el ámbito de la lengua, lo que observamos ahora es un consenso absoluto $(\mathrm{IOP}=97,3 \%)$ en torno a la creencia de que es mejor que casi todo el mundo comparta la misma lengua. También se observa un alto grado de polarización, pues el 42,2\% de los europeos optan por la respuesta extrema, es decir, por señalar que están muy de acuerdo con esa afirmación. Cuando se pregunta sobre la conveniencia de compartir costumbres y tradiciones, el índice se mantiene relativamente alto (IOP $=66,4 \%$ ) y alcanza la cota del consenso, si bien en este caso el grado de polarización es bajo, ya que tan sólo un 15,3\% señala estar muy de acuerdo, mientras que un 35,6\% elije la respuesta moderada del simple acuerdo. Así, en este caso, nos encontramos con un consenso escasamente polarizado a favor de la uniformidad de costumbres y tradiciones. En términos de valores sociales, una polarización escasa puede interpretarse como una baja implicación de los individuos o como una baja carga emocional asociada a la defensa de este valor. Además, es importante subrayar el alto nivel de indecisos, ya que un $21,6 \%$ de la población europea manifiesta no estar ni de acuerdo ni en desacuerdo. Por último, con respecto a la convivencia de gentes de distinta religión, nos encontramos con una situación fáctica de disenso social (IOP $=42,2 \%$ ), si bien con un balance escorado hacia la pluralidad religiosa (IOP $=57,8 \%)$. Aquí volvemos a encontrarnos con un menor grado de polarización y con mayor grado de indecisión, ya que casi uno de cada tres europeos $(29,5 \%)$ no tiene una opinión definida sobre si es mejor o no para el país que convivan gentes de distintas religiones. Ahora bien, teniendo en cuenta el arraigo que tiene en Europa el principio de libertad religiosa, así como el intenso proceso de secularización, este disenso puede estar indicándonos más la escasa relevancia que hoy otorgamos a la adscripción 
Cuadro 1.b. Cohesión cultural: uniformidad y diversidad cultural

\begin{tabular}{|c|c|c|c|c|c|c|}
\hline \multirow[b]{2}{*}{ Tipo de uniformidad } & \multicolumn{5}{|c|}{ Grado de acuerdo } & \multirow[b]{2}{*}{$\mathrm{Ns} / \mathrm{Nc}$} \\
\hline & $\begin{array}{l}\text { Muy de } \\
\text { acuerdo }\end{array}$ & Acuerdo & $\begin{array}{l}\mathrm{Ni} \text { ac. } \\
\text { ni des. }\end{array}$ & Desacuerdo & $\begin{array}{l}\text { Muy } \\
\text { desac. }\end{array}$ & \\
\hline \multirow{4}{*}{$\begin{array}{l}\text { Es mejor hablar todos } \\
\text { al menos una misma } \\
\text { lengua común } \\
\text { Es mejor compartir todos } \\
\text { las mismas costumbres } \\
\text { y tradiciones } \\
\text { Es mejor que convivan } \\
\text { gentes de distintas } \\
\text { religiones }\end{array}$} & 42,2 & 48,6 & 5,7 & 2,2 & 0,3 & 1,1 \\
\hline & 15,3 & 35,6 & 21,6 & 21,4 & 4,4 & 1,6 \\
\hline & 6,3 & 31,8 & 29,5 & 22,8 & 6,5 & 3,1 \\
\hline & $\begin{array}{c}\text { Empobrece } \\
(0-1-2)\end{array}$ & $(3-4)$ & $(5)$ & $(6-7)$ & $\begin{array}{c}\text { Enriquece } \\
(8-9-10)\end{array}$ & $\mathrm{Ns} / \mathrm{Nc}$ \\
\hline $\begin{array}{l}\text { Los extranjeros, } \\
\text { ¿empobrecen o } \\
\text { enriquecen la vida } \\
\text { cultural? }\end{array}$ & 11,0 & 13,6 & 22,0 & 25,5 & 22,6 & 5,1 \\
\hline
\end{tabular}

Fuente: ESS, 2002. Elaboración propia.

religiosa, que una débil valoración de la uniformidad cultural. Dada la impronta cultural de la modernización y el cambio social, idénticos argumentos podrían esgrimirse respecto al valor de la uniformidad de las costumbres y las tradiciones.

La creencia de que los extranjeros que vienen a residir al país enriquecen nuestra cultura puede ser considerada como un indicador de valoración de la diversidad cultural. A la inversa, quienes piensan que cualquier incorporación, penetración, hibridación o alteración de la cultura nacional supone un empobrecimiento de la misma, expresan con esta opinión una preferencia por la homogeneidad cultural, por evitar en lo posible cualquier contaminación. En este sentido, los datos muestran un consenso social en el que se expresa una baja preferencia por la uniformidad (IOP $=33,8 \%$ ), si bien no es desdeñable el hecho de que uno de cada tres europeos con opinión expresen que la presencia de otras culturas empobrece o contamina la propia. Es de notar el alto porcentaje de europeos que optan por la indecisión (22,0\%). También es interesante el hecho de que, con respecto a la pluralidad religiosa, las posiciones extremas reciban un mayor número de respuestas, lo que indica un relativamente mayor grado de polarización.

La primera pregunta incluida en el cuadro 1.c contiene la idea subyacente de que la presencia de extranjeros en el país hace inevitable la aparición de conflictos tanto sociales como culturales. Corresponde a una actitud profundamente pesimista a la hora de abordar los problemas de convivencia multi- 
Cuadro 1.c. Cohesión cultural: políticas de inmigración

\begin{tabular}{|c|c|c|c|c|c|c|}
\hline \multirow[b]{2}{*}{ Tipo de política } & \multicolumn{5}{|c|}{ Grado de acuerdo } & \multirow[b]{2}{*}{$\mathrm{Ns} / \mathrm{Nc}$} \\
\hline & $\begin{array}{l}\text { Muy de } \\
\text { acuerdo }\end{array}$ & Acuerdo & $\begin{array}{l}\mathrm{Ni} \text { ac. } \\
\text { ni des. }\end{array}$ & Desacuerdo & $\begin{array}{l}\text { Muy } \\
\text { desac. }\end{array}$ & \\
\hline $\begin{array}{l}\text { Para evitar problemas y } \\
\text { tensiones, se debe poner } \\
\text { fin a la inmigración }\end{array}$ & 11,0 & 29,1 & 23,7 & 24,6 & 6,9 & 4,7 \\
\hline $\begin{array}{l}\text { Posibilidad, si lo desean, } \\
\text { de que eduquen en } \\
\text { escuelas separadas }\end{array}$ & 5,5 & 24,3 & 15,4 & 33,2 & 18,4 & 2,9 \\
\hline
\end{tabular}

Fuente: ESS, 2002. Elaboración propia.

cultural y multiétnica, ya que la única solución concebible es cortar de raíz los flujos migratorios. Pues bien, los datos expresan la existencia en la opinión pública de un disenso, con escasa polarización, orientada hacia el polo pesimista $(\mathrm{IOP}=56 \%)$, si bien hay que considerar que el porcentaje de indecisos también es muy alto $(23,7 \%)$. En cualquier caso, el resultado pone de manifiesto el sólido trasfondo de temor y de pesimismo que alimenta la valoración de la homogeneidad cultural.

Cuando se pregunta a los europeos si las «comunidades de personas» que han venido a vivir aquí deberían poder "educar a sus hijos», "si así lo desean", en "escuelas separadas», lo que observamos es un ligero consenso en contra de que las comunidades culturales puedan socializar a sus miembros en escuelas separadas, es decir, en contra de la segregación educativa, incluso voluntaria $(\mathrm{IOP}=36,6 \%)$. La interpretación de esta pregunta es muy compleja, pues en su respuesta influyen algunas de las más importantes claves ideológicas que afectan a la valoración de la uniformidad o de la diversidad cultural. Así, por ejemplo, la defensa de la segregación educativa podría estar justificada por la alta valoración que el entrevistado concede a la diversidad cultural. Sin embargo, esa misma defensa podría estar basada en una nítida actitud excluyente, en la voluntad de que los extranjeros vivan espacialmente aquí, pero que vivan segregados socialmente. A la inversa, el rechazo a la segregación educativa podría estar justificado por el deseo de no discriminar educativamente a los niños de las diversas comunidades culturales, pero también podría deberse a una voluntad integracionista o asimilacionista que pasa por la rigurosa aplicación de una política educativa universalista. En cierto modo, esta pregunta nos enfrenta de lleno con las más importantes paradojas y contradicciones morales que subyacen en el debate público del multiculturalismo y del monoculturalismo. De ahí que dar una respuesta éticamente coherente a esta pregunta comporte, salvo para los ingenuos morales, una extrema dificultad.

Recapitulando los índices de opinión pública orientados a la defensa de la uniformidad cultural, hemos visto que tanto la homogeneidad «lin- 
güística» (IOP = 80,4\% y 97,3\%), como la referente al «modo de vida» $(\mathrm{IOP}=88,1 \%)$, alcanzan una altísima valoración, con lo cual llegan a constituir grandes consensos, casi absolutos, de la cultura europea. En segundo lugar, hemos visto que la valoración de la homogeneidad cultural referente a "costumbres y tradiciones» es también bastante alta (IOP $=66,4 \%$ ), lo que demuestra la existencia de un sólido consenso a este respecto. La homogeneidad religiosa es bastante menos valorada, aunque, por término medio, es defendida por uno de cada tres europeos (IOP $=31,5 \%$ y $42,2 \%$ ), cantidad nada despreciable teniendo en cuenta el grado de secularismo de la cultura europea. Por último, una gran parte de los europeos entiende que la entrada de extranjeros enriquece nuestra cultura, si bien el porcentaje de quienes piensan que la empobrece tampoco es nada despreciable $(\mathrm{IOP}=33,8 \%)$.

En suma, sobre el trasfondo de una valoración generalizada de la uniformidad cultural por parte de los europeos, se dibujan importantes variaciones que afectan a los distintos elementos de la cultura. En el epígrafe siguiente, trataremos de ahondar en la interpretación de estas variaciones, pero, desde una primera inducción analítica, intuimos que algunas de las diferencias pueden estar relacionadas con las características asociadas a cada elemento de la cultura. En primer lugar, existe un contraste entre rasgos superficiales o epidérmicos y rasgos profundos de la cultura. Así, es obvio que admitir el enriquecimiento de la diversidad cultural no tiene la misma relevancia que admitir la presencia en el interior de un país de diferentes lenguas o modos de vida. En segundo lugar, también existe un contraste entre rasgos instrumentales y rasgos expresivos de la cultura que pudieran estar en el origen de algunas variaciones en la valoración de la uniformidad cultural. Así, es obvio que el idioma o el modo de vida presentan un grado de instrumentalidad que contrasta con el fuerte contenido expresivo que puedan tener las costumbres y las tradiciones o la misma adscripción religiosa.

\section{El monoculturalismo y el multiculturalismo}

Según hemos visto en el análisis univariable de las diez opiniones valorativas, podemos suponer que las respuestas dadas por cada entrevistado a este conjunto de preguntas tendrán alguna coherencia, es decir, que tales respuestas vendrán determinadas en parte por la general adscripción del individuo a valores monoculturalistas o multiculturalistas. Al mismo tiempo, hemos observado variaciones en las respuestas que parecen estar relacionadas con el contenido semántico de las mismas, es decir, con las características o los rasgos del componente cultural referido por la pregunta. Pues bien, para comprobar que, en efecto, existe un valor general o una dimensión valorativa que subyace a este conjunto de opiniones, y para comprobar hasta qué punto las variaciones observadas dependen de algún factor subyacente vinculado a la naturaleza de los diversos elementos de la cultura, hemos realizado una exploración multivariable, analítico-interpretativa, aplicando la técnica del Análisis de Componentes 
Cuadro 2. Análisis de componentes principales categóricos. Saturación de los componentes

\section{Dimensiones}

\begin{tabular}{lcc}
\cline { 2 - 3 } Variables & D1 (Grado) & D2 (Tipo) \\
\hline $\begin{array}{l}\text { Mejor si casi todos } \\
\text { compartimos costumbres }\end{array}$ & $-0,720$ & \\
$\begin{array}{c}\text { y tradiciones } \\
\text { Mejor si hay variedad } \\
\text { de diferentes religiones }\end{array}$ & 0,529 & $-0,238$ \\
$\begin{array}{c}\text { Mejor si casi todos hablan } \\
\text { el mismo idioma }\end{array}$ & $-0,350$ & 0,472 \\
$\begin{array}{l}\text { Inmigr.: importancia } \\
\text { hablar mismo idioma }\end{array}$ & 0,582 & 0,628 \\
$\begin{array}{c}\text { Inmigr.: importancia } \\
\text { proceder de país de } \\
\text { cultura cristiana }\end{array}$ & 0,602 & $-0,509$ \\
$\begin{array}{c}\text { Inmigr.: importancia } \\
\text { del compromiso con } \\
\text { el modo de vida }\end{array}$ & 0,663 & \\
$\begin{array}{l}\text { Inmigr.: enriquece o } \\
\text { empobrece la vida } \\
\text { cultural }\end{array}$ & $-0,600$ & 0,281 \\
\hline
\end{tabular}

Fuente: ESS, 2002. Elaboración propia.

Principales Categóricos ${ }^{2}$. Tras una fase exploratoria, se obtuvo una solución factorial en la que, utilizando siete de las diez variables analizadas, se extrajeron dos factores o dimensiones.

La primera dimensión obtenida explica un $34,6 \%$ de la varianza total, mientras que la segunda explica un $18,5 \%$ de esa misma varianza. Así pues, la varianza explicada por ambas dimensiones es del 53,1\%. En el cuadro 2, se han incluido los autovalores o grado en el que cada una de las siete variables satura cada una de las dos dimensiones. En los datos de este cuadro, puede observarse, primero, que todas las variables, salvo una, muestran altos grados de saturación del primer factor y, segundo, que las variables saturan con muy diversos grados la segunda de las dimensiones. El primer hecho puede interpretarse en el sentido de que, en efecto, existe una dimensión subyacente a

2. La estrategia metodológica es similar a la utilizada en E. BERICAT y J. DEL PINO (1998), Valores sociales en la cultura andaluza, Madrid, CIS. Frente al uso común de la técnica factorial, en la que se introducen un gran número de variables con un alto grado de diversidad en su contenido semántico, mi estrategia consiste en introducir en el análisis variables con un contenido semántico similar. Esto permite obtener una dimensión común subyacente a todas ellas, así como profundizar en el análisis de los matices o diferencias, tanto semánticas como pragmáticas, que incorpora el conjunto. Como ejemplos interesantes del uso más extendido de la técnica factorial, pueden verse: CEA D’ANCONA (2004) y SORA (2001). 
todas las variables. El hecho de que las dos variables referidas a la homogeneidad lingüística sean las que más saturen la segunda dimensión $(0,628$ y $-0,509)$ nos indica la existencia de un factor subyacente que discrimina según la naturaleza del elemento cultural considerado.

Ahora bien, la interpretación teórica de ambos factores se pone de manifiesto con mucha mayor claridad en el gráfico 1, en el que están representadas las puntuaciones medias que obtienen en cada uno de los factores el conjunto de entrevistados que han elegido una determinada categoría de respuesta. Analizando las posiciones de estas categorías, podemos concluir que la primera dimensión (eje horizontal) puede interpretarse como una medida del grado de valoración de la uniformidad o de la diversidad cultural. La segunda dimensión constituye una media del tipo de valoración, sea monoculturalista o multiculturalista, que realizan los entrevistados.

Interpretamos que la dimensión 1 se corresponde con el grado de monoculturalismo o de multiculturalismo que manifiestan los europeos respondiendo a las siete preguntas incluidas en el análisis multivariable. Proyectando la posición de las categorías de respuesta sobre el eje horizontal, veremos que, en la parte derecha del gráfico, se ubican las categorías de las siete variables que están asociadas a una valoración positiva de la uniformidad cultural (valores positivos de la dimensión 1). Así mismo, las categorías asociadas a la defensa y a la valoración positiva de la diversidad cultural se ubican en la parte izquierda del gráfico (valores negativos de la dimensión 1). Desde esta perspectiva, resulta muy interesante observar con más detalle las posiciones que ocupan en el gráfico las categorías de respuesta, pues cada una de ellas implica un grado muy diferente de monoculturalismo o de multiculturalismo. Así, por ejemplo, responder que, como criterio de entrada, es muy importante (posición 11 de la escala) que el inmigrante proceda de un país de tradición cristiana equivale a un altísimo grado de monoculturalismo. Sin embargo, haber respondido estar «muy de acuerdo» en que casi todo el mundo hable la misma lengua equivale a un grado moderado de monoculturalismo.

Interpretamos que la dimensión 2 se corresponde con dos tipos de monoculturalismo y de multiculturalismo que están vinculados a dos concepciones diferentes de la cultura, una pragmatista y otra esencialista. Observando la panorámica general que nos muestra el gráfico 1, podemos comprobar la existencia de dos haces o grupos de variables. En un racimo, se encuentran tres variables, dos que aluden a la homogeneidad lingüística y una a la homogeneidad en el modo de vida. El otro racimo se compone de cuatro variables: la valoración de la uniformidad de costumbres y tradiciones, las dos variables que hacen referencia a la religión y, por último, la que alude a si los extranjeros inmigrantes enriquecen o empobrecen la cultura. Así, comprobamos que, en efecto, el segundo factor discrimina según la naturaleza del elemento cultural incluido en la pregunta. Ahora nos queda interpretar el sentido de tal discriminación.

En una primera aproximación teórica, podríamos decir que la defensa de la homogeneidad tanto "lingüística» como de "modo de vida» deben interpretarse como indicadores de una mayor consideración de los aspectos prác- 


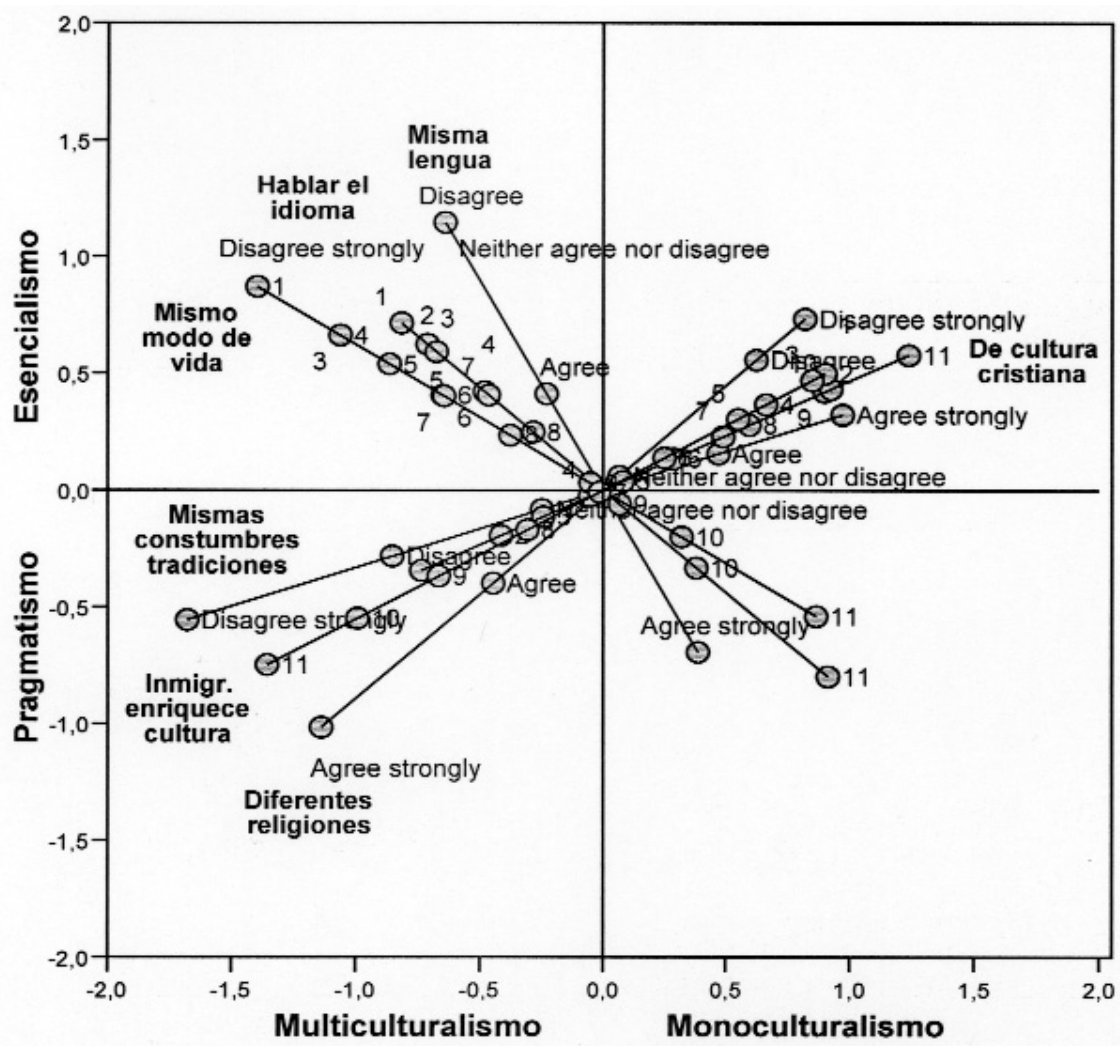

Gráfico 1. Grado y tipo de valoración monoculturalista y multiculturalista (puntuación de las categorías).

ticos, instrumentales y funcionales asociados al valor de la uniformidad cultural. Sin un adecuado conocimiento del mismo idioma, la interacción sociofuncional entre personas resulta mucho más difícil y complicada. Por tanto, la homogeneidad lingüística puede contemplarse como un mero requisito funcional del sistema. Por otro lado, el concepto de modo de vida remite a las pautas culturales y de comportamiento tal y como aparecen en el tiempo presente de un determinado sistema social, de ahí que también pueda considerarse que la diversidad de modos de vida dificultaría funcionalmente tanto la organización como la interactividad social. Este sentido pragmático presente en las valoraciones monoculturalistas queda perfectamente reflejado en el argumento de John Rex:

No creo que en estos estados nación, la cultura nacional o el sistema institucional de la sociedad mayoritaria de asentamiento puedan ser vistos sim- 
plemente como una cultura más entre numerosas culturas. Yo supongo que habrá una lengua nacional oficial (o más de una), un código civil y penal, una economía nacional y un sistema educativo nacional. Lo que los inmigrantes deben de aceptar - y creo que de hecho aceptan- es que tienen que aprender a vivir dentro de este sistema de instituciones [...] Por lo tanto, tendrán que aprender a ser cultural y políticamente bilingües, porque, aunque conserven su cultura y sus costumbres propias en cuestiones de su comunidad, actuar en el mundo de la economía y de la política requiere un conocimiento fluido de la cultura y la lengua del ámbito público de la mayoría (Rex, 1995: 203).

Al contrario, cuando concebimos el valor de la uniformidad cultural otorgando mayor relevancia a la homogeneidad «religiosa» y de «costumbres y tradiciones», o prestando mayor atención al hecho de que la entrada de extranjeros inmigrantes «empobrecería la cultura» de nuestro país, mostramos una muy diferente concepción de la cultura. En este caso, entendemos que nuestra cultura está vinculada, en esencia, a las costumbres, a las mores y a las tradiciones más profundamente arraigadas en nuestra sociedad, esto es, a un conjunto de prácticas y universos simbólicos que han persistido en el tiempo y que aún permanecen vivos. Desde esta perspectiva, la religión formaría parte indisociable del núcleo esencial de las culturas. Compartir la cultura no implicaría, tan sólo, conocer el idioma o ajustarse a las normas, a los modos y estilos de vida vigentes en una sociedad, sino comprender y compartir el sentido de la vida que ha sido conformado a lo largo del tiempo por nuestra esencia cultural. Por tanto, es obvio que quienes se adscriban a esta concepción esencialista de la cultura, entiendan que cualquier interpenetración, hibridación o contacto cultural implicaría un riesgo de contaminación, en ningún caso un enriquecimiento, sino un empobrecimiento que puede alterar la esencia de su cultura. En gran medida, el contraste entre la concepción pragmática y la concepción esencialista de la cultura, como bien señala Lamo de Espinosa (1995b), está presente en las obras de Montesquieu y Herder, así como en la tradición intelectual de la Ilustración francesa y del Romanticismo alemán.

Proyectando ahora las posiciones de las categorías sobre el eje vertical del gráfico 1, observaremos que, en la parte superior (esencialismo), se encuentran las categorías asociadas a altas valoraciones de la uniformidad cultural de tipo esencialista y las asociadas a bajas valoraciones de la uniformidad de tipo pragmatista. Al contrario, en la parte inferior del gráfico (pragmatismo), se ubican aquellas categorías asociadas con una alta valoración de la uniformidad pragmática y con una baja valoración de la uniformidad esencialista. Pues bien, cruzando la información de las dos dimensiones, obtenemos un plano de cuatro cuadrantes que representarían los cuatro tipos o posiciones culturales básicas que muestran los europeos en torno al debate del multiculturalismo, esto es, monoculturalismo esencialista, monoculturalismo pragmático, multiculturalismo pragmático y multiculturalismo esencialista. Atendiendo a estos resultados, llegamos a una importante conclusión: el mero posicionamiento monotónico establecido exclusivamente en términos del grado en que valoramos la diversidad o la 
uniformidad cultural, no es suficiente para fijar la posición ideológica de un individuo o de un colectivo en el debate acerca del multiculturalismo.

\section{La estructura básica del debate acerca del multiculturalismo}

Tal y como ha puesto de manifiesto el análisis de componentes principales categóricos realizado, el debate acerca del multiculturalismo se estructura en cuatro posicionamientos. El contenido moral, ideológico y político de cada uno de ellos se expone en los párrafos siguientes.

Monoculturalismo esencialista: la adscripción a este monoculturalismo extremo se corresponde con una defensa a ultranza, radical y cerrada, de la homogeneidad cultural, esto es, a un fundamentalismo cultural que observa con mucho recelo la entrada de «otros» que puedan poner en riesgo la integridad y la identidad nacional. La presencia del diferente, en sí misma, constituye una fuente de inseguridad ontológica, cultural, moral y social. El otro siempre resulta absolutamente incomprensible e ininteligible, por ello peligroso. La valoración de las otras culturas, y de la diversidad cultural en sí misma, es nula, cuando no explícitamente negativa o despreciativa. El fundamentalismo cultural, en palabras de Stolcke, invoca una concepción de la cultura contradictoriamente inspirada tanto por la tradición del universalismo ilustrado, como por el romanticismo germánico que marcó gran parte del debate nacionalista durante el siglo XIX (Stolcke, 1995: 8). Su traducción política consiste en la aplicación de una estrategia de asimilación o integración total del otro. Desde la perspectiva de un monoculturalismo esencialista, que cosifica y objetiva nuestra cultura en sus elementos identitarios más tradicionales, la incorporación de otras tradiciones culturales a la propia supondría, necesariamente, bien una degradación civilizatoria, bien una contaminación que reduce la pureza de nuestra esencia cultural.

Monoculturalismo pragmático: éste es un tipo de monoculturalismo moderado que no está basado en la defensa, a veces desesperada y numantina, del centro de gravedad esencial que anima y da sentido a las culturas nacionales. En este posicionamiento, la defensa de las esencias culturales permanece como telón de fondo del discurso, sin adquirir un papel ni protagonista ni relevante. Lo que importa mucho es el mantenimiento de las pautas de vida y de los modos básicos de organización social vinculados al funcionamiento de la interacción social y al logro de los desempeños del sistema. No tiene por qué presuponer la superioridad de la cultura nacional, ni apoyarse en un etnocentrismo declarado. En su orientación de política positiva, el monoculturalismo pragmático esgrime una defensa de los prerrequisitos funcionales del sistema social, en el sentido parsoniano del término. En su orientación de política negativa, la coexistencia de comunidades monoculturales diversas contiene unos riesgos de violencia, de sufrimiento y de crueldad social que hay que evitar. La posición pragmática de Rex, en la que el otro tiene que y debe de integrarse, por meras razones funcionales, en el modo de vida de la sociedad recep- 
tora, constituye un ejemplo de orientación monocultural funcionalista de carácter positivo. Rex combina una asimilación funcional en el ámbito de lo público, con un respeto esencialista hacia las culturas en el ámbito de lo privado. Jacob T. Levy, con su multiculturalismo del miedo, representaría la orientación negativa del monoculturalismo pragmático. Levy se centra en el desarrollo de una teoría política liberal orientada a mitigar los peligros, la violencia, la crueldad y la humillación que pueden surgir de la gestión política del contacto entre homogeneidades culturales diversas.

Multiculturalismo pragmático: la adscripción a este tipo de multiculturalismo implica, en sentido general, una valoración positiva de la existencia de diversidad cultural en el seno de una sociedad nacional. Este reconocimiento implícito de las culturas no es, sin embargo, absoluto. Así, Lamo de Espinosa habla del «respeto a las identidades culturales, no como reforzamiento de su etnocentrismo, sino, al contrario, como camino, más allá de la mera coexistencia, hacia la convivencia, la fertilización cruzada y el mestizaje (Lamo, 1995: 18). Las dos claves del discurso multicultural pragmático son el reconocimiento del ser humano como "ser de cultura», y la necesidad del diálogo intercultural. Este diálogo entre culturas no es sólo instrumentalmente necesario para la convivencia, sino que nos aporta la posibilidad de un aprendizaje y de un reconocimiento. También contiene un claro imperativo ético: «cuando defendemos la diversidad, estamos invitando a escuchar al otro» (Jahanbegloo, 2007). Una versión diluida del multiculturalismo pragmático nos llevaría a la mera «exaltación cosmética de la diversidad cultural» (Isar, 2006: 374), así como a un aprovechamiento epidérmico de las potencialidades de enriquecimiento implícitas en el diálogo intercultural. En esta versión diluida, se descomponen las culturas hasta hacerlas aptas para el consumo individualista de un cosmopolitismo banal al que hace referencia Amin aludiendo a Beck. Esto es, «mezcla e hibridación, en el ámbito de la vida cotidiana, y fundamentalmente a través de prácticas de consumo, de múltiples rasgos culturales, múltiples identidades y múltiples sentidos de identificación territorial» (Amin, 2004: 8).

Multiculturalismo esencialista: este tipo de multiculturalismo establece un absoluto respeto por todas las culturas y una valoración positiva de cada una de ellas, en tanto producciones singulares desarrolladas históricamente por la humanidad. Comporta una exaltación no epidérmica de la esencia de cada cultura, considerada sintéticamente como un todo que no admite la descomposición de sus elementos constituyentes básicos. Todas ellas cobrarían sentido y valor en función de un "centro de gravedad» esencial, según la terminología de Herder, que las define. Además, al considerar que la cultura constituye una producción necesariamente grupal, va más allá de la mera aceptación de «diferencias culturales», llegando al pleno reconocimiento público e incluso político de cada identidad social. La pertenencia del individuo al grupo constituye un bien primario y natural que es necesario preservar. En suma, el multiculturalismo esencialista implica una concepción comunitaria y una idea objetiva, y, en cierto sentido, bastante cerrada, de todas las culturas. El pluri- 
Cuadro 3. Distribución porcentual de la población europea, según grado y tipo de valoración de la uniformidad cultural

\begin{tabular}{lccccc}
\hline $\begin{array}{l}\text { Grado (D1) } \\
\text { Tipo (D2) }\end{array}$ & $\begin{array}{c}\text { Muy } \\
\text { multicultural } \\
(\text { menor que -1) }\end{array}$ & $\begin{array}{c}\text { Multicultural } \\
(\text { entre 0 y -1) }\end{array}$ & $\begin{array}{c}\text { Monocultural } \\
(\text { entre 0 y +1) }\end{array}$ & $\begin{array}{c}\text { Muy } \\
\text { monocultural } \\
(\text { mayor que +1) }\end{array}$ & Total \\
\hline $\begin{array}{l}\text { Muy esencialista } \\
\text { (mayor que +1) }\end{array}$ & 1,6 & 7,3 & 7,0 & $1,5 \%$ & 17,4 \\
$\begin{array}{l}\text { Esencialista } \\
\text { (entre 0 y +1) }\end{array}$ & 6,2 & 11,9 & 10,6 & $5,7 \%$ & 34,4 \\
$\begin{array}{l}\text { Pragmático } \\
\text { (entre 0 y -1) }\end{array}$ & 5,5 & 8,8 & 9,5 & $7,4 \%$ & 31,2 \\
$\begin{array}{l}\text { Muy pragmático } \\
\text { (menor que -1) }\end{array}$ & 2,9 & 5,5 & 5,6 & & \\
Total & 17,3 & 32,7 & 33,5 & 16,2 & 16,7 \\
\hline
\end{tabular}

Fuente: ESS, 2002. Elaboración propia.

centrismo y el pluralismo moral caracterizarían en gran parte a esta posición, si bien ello no tendría que abocar necesariamente en un absoluto relativismo cultural, aunque sí en un rotundo rechazo a la aplicación de cualquier moral universalista desde la que se pretenda juzgar al resto de las culturas. Desde un multiculturalismo comunitarista, que valora las virtudes derivadas del cierre cultural, social e identitario que instituyen las comunidades, la clave de la coexistencia estaría, según Waldrom, en el establecimiento de un derecho cosmopolita (Levy, 2000: 64) constituido por un conjunto de normas y leyes orientadas a regular y ordenar las interrelaciones, potencialmente cooperativas o conflictivas, entre las diversas comunidades culturales.

Visto el contenido de los cuatro posicionamientos incluidos en esta tipología, mostraremos ahora algunas descripciones empíricas utilizando las cuantificaciones, obtenidas mediante el análisis de componentes principales categóricos, del "grado» y del «tipo» de valoración de la uniformidad o de la diversidad cultural. En primer lugar, ofrecemos el porcentaje de europeos que se adscriben a cada una de las posiciones (cuadro 3). En segundo lugar, describimos el contenido de los tipos en función de los porcentajes de repuesta dados por cada uno de ellos a las preguntas originales (cuadro 4). En tercer y último lugar, presentamos el posicionamiento de los países europeos en el plano constituido por ambas dimensiones (gráfico 2).

En la distribución porcentual de la población europea que presentamos en el cuadro 3, hemos querido mantener la partición estadística de la masa total que establece la técnica multivariable. Ente otras razones, porque toda partición es convencional, pero, fundamentalmente, porque tal partición se adapta a nuestro propósito de cuantificar cuántos europeos muestran posiciones extremas en el debate sobre el multiculturalismo. Estas posiciones están bien representadas por los entrevistados que obtienen puntuaciones superiores a $+1 \mathrm{o}$ inferior a -1 en ambas dimensiones. Tal y como podemos observar en los datos 
Cuadro 4. Tipología del multiculturalismo: contenido descriptivo

\begin{tabular}{|c|c|c|c|c|c|c|}
\hline \multirow[b]{2}{*}{ Variables } & \multicolumn{6}{|c|}{ Tipos } \\
\hline & $\begin{array}{c}\text { Muy } \\
\text { monocultural }\end{array}$ & Monocultural & Multicultural & $\begin{array}{c}\text { Muy } \\
\text { multicultural }\end{array}$ & $\begin{array}{c}\text { Muy } \\
\text { monocultural } \\
\text { Esencialista }\end{array}$ & $\begin{array}{c}\text { Muy } \\
\text { monocultural } \\
\text { Pragmático }\end{array}$ \\
\hline Hablar la lengua del país (MI) & 88,6 & 61,5 & 36,3 & 17,1 & 95,9 & 97,7 \\
\hline $\begin{array}{l}\text { Hablar todos al menos una } \\
\text { misma lengua común }(\mathrm{M})\end{array}$ & 72,7 & 46,7 & 30,7 & 25,0 & 95,1 & 98.9 \\
\hline Adoptar el modo de vida (MI) & 94,3 & 75,2 & 46,5 & 15,5 & 88,8 & 98,2 \\
\hline Proceda de un país cristiano (MI) & 47,8 & 15,4 & 2,8 & 0,2 & 61,6 & 36,1 \\
\hline $\begin{array}{l}\text { Que convivan gentes de distintas } \\
\text { religiones }(M+B)\end{array}$ & 10,9 & 27,2 & 45,8 & 74,3 & 1,9 & 17,3 \\
\hline $\begin{array}{l}\text { Compartir todos las mismas } \\
\text { costumbres y tradiciones }(M+B) \\
\text { Inmigrantes: enriquecen la vida }\end{array}$ & 93,7 & 72,1 & 31,5 & 3,6 & 96,5 & 91,7 \\
\hline $\begin{array}{l}\text { cultural (mucho }=8 \text { a } 10) \\
\text { Posibilidad de educar en escuelas }\end{array}$ & 3,2 & 11,2 & 24,4 & 63,1 & 0,9 & 4,9 \\
\hline $\begin{array}{l}\text { separadas }(M+B) \\
\text { Para evitar problemas: poner fin }\end{array}$ & 25,5 & 29,2 & 29,7 & 36,8 & 29,0 & 23,0 \\
\hline a inmigración $(\mathrm{M}+\mathrm{B})$ & 72,3 & 50,4 & 28,4 & 9,9 & 75,9 & 69,8 \\
\hline
\end{tabular}

Notaciones: $\mathrm{M}=$ muy de acuerdo $\mathrm{M}+\mathrm{B}=$ muy + bastante de acuerdo; $\mathrm{MI}=$ muy importante, $8-10$.

Fuente: ESS, 2002. Elaboración propia. 


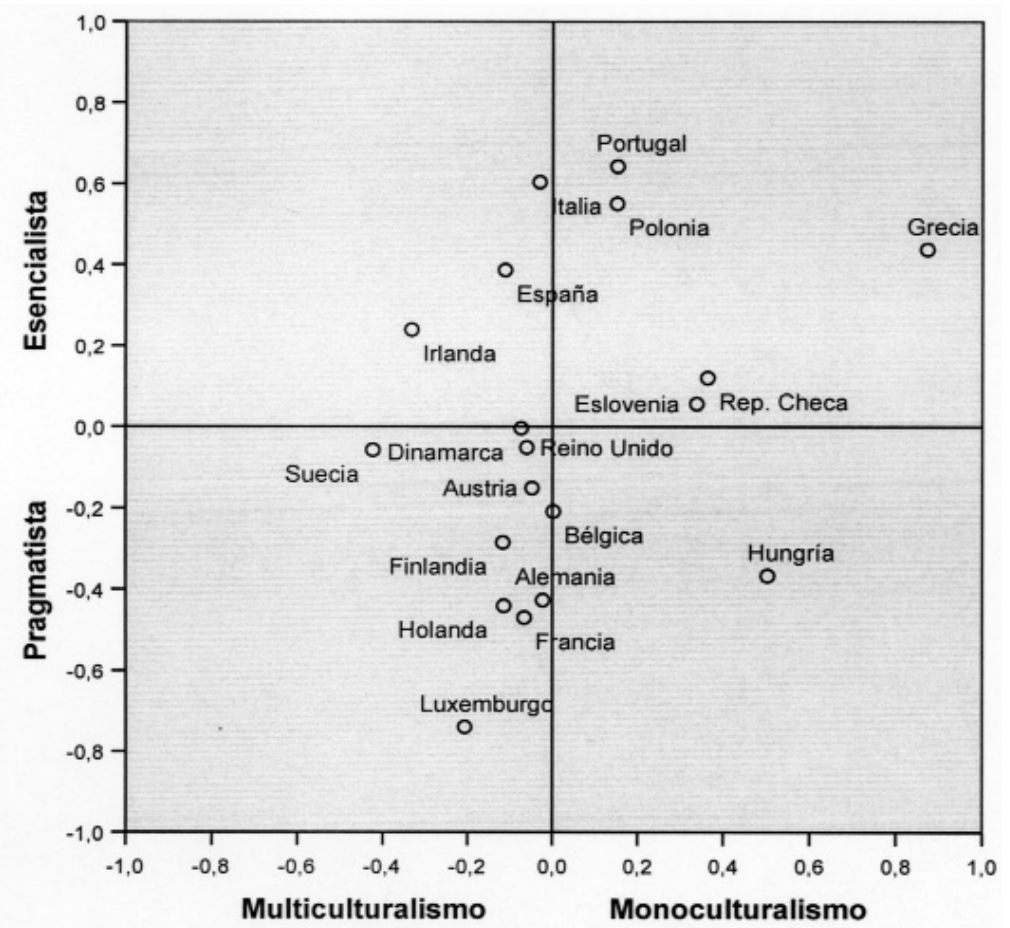

Gráfico 2. Posicionamiento de los países europeos, según grado y tipo de valoración de la uniformidad cultural. Fuente: ESS, 2002. Elaboración propia.

del cuadro 4, los tipos establecidos difieren substancialmente en términos de las respuestas dadas a las variables originales y, además, los extremos casi se corresponden con tipos puros.

Los europeos «muy monoculturales» abogan de una forma consistente y sistemática por la defensa de la uniformidad cultural: el $88,6 \%$ y el $72,7 \%$ defiende con valores extremos la homogeneidad lingüística; el 94,3\%, la uniformidad del modo de vida; el 93,7\%, la uniformidad de costumbres y tradiciones; el $89,1 \%$ no está de acuerdo en que convivan distintas religiones; el 96,8\% cree que los inmigrantes empobrecen la cultura, y el 72,3\% considera que, para evitar problemas, es mejor poner fin a la inmigración. Como hemos mencionado, este grupo constituye casi un tipo puro, compuesto por un 16,2\% de europeos que mantienen claras y rotundas convicciones monoculturales. Incluso cuando se trata de señalar la importancia de proceder de un país de tradición cristiana como criterio de entrada de inmigrantes, casi la mitad de ellos opta por el extremo de la escala, esto es, por la categoría de respuesta 8, la 9 o la 10.

En el cuadro 4, vemos cómo los porcentajes van variando sistemáticamente conforme nos acercamos al polo multicultural de la tipología. Sin embargo, 
este tipo no resulta ser técnicamente tan puro, pues la uniformidad lingüística y del modo de vida no obtiene un rechazo total. Sin embargo, es muy contundente la defensa, en los muy multiculturales, del pluralismo religioso o el rechazo a la uniformidad de costumbres y tradiciones. En las columnas más a la derecha de este mismo cuadro, pueden observarse el perfil de rasgos que caracteriza a los europeos «muy monoculturales», según sean más pragmáticos o más esencialistas. Los pragmáticos superan a los esencialistas en su valoración de la homogeneidad lingüística y de modo de vida, que llega en este tipo a ser prácticamente del $100 \%$. En cambio, los esencialistas otorgan una importancia altísima, casi absoluta, a la uniformidad religiosa y tradicional. Asimismo, se detectan diferencias porcentuales en la posibilidad de educar en escuelas separadas, que los esencialistas aceptan en mayor medida $(29,0 \%)$ que los pragmáticos $(23 \%)$. Los esencialistas entienden que el problema de coexistencia cultural es más irresoluble, y de ahí que defiendan en mayor medida $(75,9 \%)$ que los pragmáticos $(69,8 \%)$ poner fin a la inmigración.

Gracias a que el Análisis de Componentes Principales Categóricos imputa a cada entrevistado una puntuación en cada una de las dimensiones, podemos desarrollar múltiples análisis calculando los índices (medias estadísticas) de monoculturalidad y/o de esencialismo cultural de diversos colectivos sociales y agregados estadísticos. Podemos, por ejemplo, comparar a este respecto las culturas de los diferentes países europeos incluidos en la muestra. La primera conclusión que puede extraerse del gráfico 2 es la influencia que tienen las culturas nacionales sobre la adscripción a valores que muestran los individuos.

Proyectando las posiciones de cada país sobre el eje horizontal, comprobamos que Suecia $(-0,42)$ es el país con mayor grado de valoración del multiculturalismo, mientras que Grecia $(0,87)$ constituye el país con la mayor valoración del monoculturalismo, una valoración próxima al 1, lo que significa que, por término medio, los griegos tienen un perfil de respuestas parecido al tipo «muy monocultural» expuesto en el cuadro 4. Las diferencias nacionales en el grado de pragmatismo o esencialismo a la hora de concebir la cultura, también son reseñables. Vemos que, en la parte superior del gráfico (polo esencialista), se ubica un conjunto de países, como Portugal, Italia, Polonia, España e Irlanda, caracterizados por una fuerte tradición católica. Si bien comparten una concepción esencialista de la cultura, su grado de multiculturalismo es muy diverso. Observando sus posiciones relativas, puede decirse que, en el contexto de los países católicos, un mayor grado de esencialismo parece estar correlacionado con un grado mayor de monoculturalismo. A este respecto, vemos que España ocupa una posición singular, bastante diferenciada del resto, pues, siendo un país católico y monorreligioso, presenta un relativamente alto grado de multiculturalismo y un relativamente bajo grado de esencialismo, lo que nos remite al intenso y rápido proceso de modernización cultural que está siguiendo, así como al profundo proceso de secularización que está afectando a su cultura.

En la parte inferior del gráfico no se encuentra ningún país con fuerte tradición católica, salvando la excepción de Francia, que, como puede verse, constituye el país con una concepción cultural más pragmatista (excluido 
Luxemburgo). Sin duda, el posicionamiento de los franceses puede interpretarse como el persistente reflejo de una tradición iniciada en el Siglo de las Luces, condensada culturalmente en la Ilustración y plasmada políticamente en la Revolución Francesa y en su modelo republicano. Como es bien sabido, este modelo político está íntimamente conectado con el modelo de integración ciudadana que Francia aplica a los inmigrantes, modelo en el que apenas existen políticas de reconocimiento a ninguna comunidad cultural. Así, la concepción pragmatista de la cultura puede entenderse en el marco de este complejo político-cultural típicamente francés, y típicamente "moderno" y "europeo». Desde una perspectiva ilustrada y moderna, la cultura no contiene una esencia inalterable que se perpetúa a través del tiempo por medio de las costumbres, las tradiciones y la religión, sino que constituye el concreto y particular despliegue de un modo de vida que los individuos acuerdan mediante un contrato social actualizado permanentemente en el marco de la legalidad democrática y de la interacción social de individuos libres e iguales entre sí. La negación de los derechos colectivos y comunitarios forma también parte de este ethos cultural, alejado de supuestas esencias colectivas que puedan imponerse a la libre y actual decisión de los individuos.

En el gráfico, la posición de Francia forma una especie de conglomerado con otros dos países, Holanda y Alemania. Pese a la diferente naturaleza de la inmigración en Francia y Alemania, y pese a sus diferentes tradiciones culturales, la población de ambos países parece compartir una misma concepción de la cultura y un mismo grado de monoculturalismo. En ningún caso presentan un alto grado de multiculturalismo, y en todos ellos su concepción de la cultura es bastante pragmatista, lo que explicaría la debilidad o ausencia de adecuadas políticas de reconocimiento orientadas hacia las comunidades culturales, étnicas o identitarias. Los estados se preocupan de integrar al inmigrante, en la medida de sus posibilidades y con muy diversos grados de éxito, en tanto ciudadano universal o en tanto trabajador, pero nunca en cuanto sujeto de cultura e identidad que ponga en peligro, mediante diversas segmentaciones sociales, el universalismo desde el que opera el estado. A este respecto, la posición del Reino Unido difiere sensiblemente, de ahí que ocupe una posición central en el gráfico. Su grado de multiculturalismo es similar al de Francia o al de Alemania, pero su concepción de la cultura se orienta más hacia el esencialismo. De ahí que, en el modelo de integración del Reino Unido, exista cierto lugar para el reconocimiento de la diversidad cultural, tal y como puede manifestarse colectivamente en su vertebración comunitaria, étnica o identitaria.

\section{Posicionamiento ideológico y multiculturalismo}

Desde la perspectiva del multiculturalismo del miedo, defendida por Jacob T. Levy, es evidente que los mayores peligros para una coexistencia multicultural pacífica proceden de las prácticas crueles y/o humillantes que puedan llevar a cabo mayorías o minorías con el propósito de alcanzar en su seno altos grados de monoculturalidad fáctica. Suponemos que estos propósitos estarán vincu- 

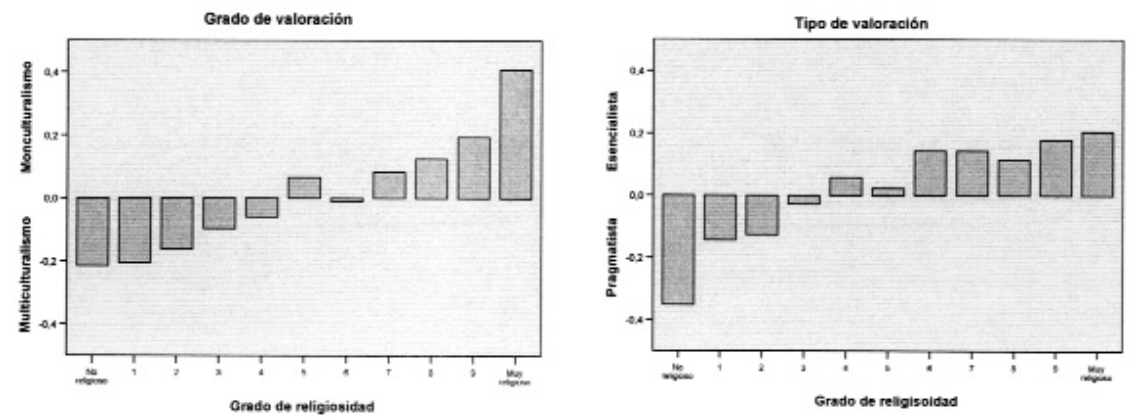

Gráfico 3a. Grado y tipo de valoración de la uniformidad cultural, según grado de religiosidad. Fuente: ESS, 2002. Elaboración propia.
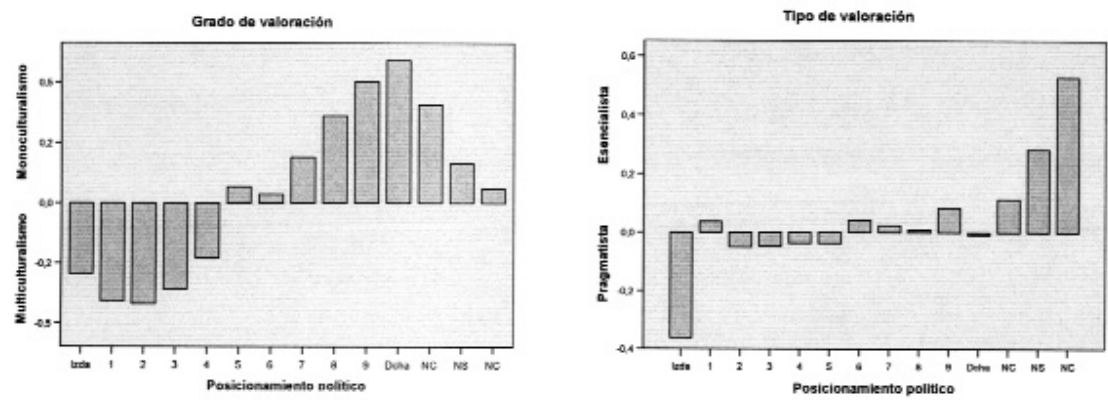

Gráfico 3b. Grado y tipo de valoración de la uniformidad cultural, según autoposicionamiento ideológico. Fuente: ESS, 2002. Elaboración propia.

lados a un alto grado de monoculturalismo normativo, esto es, a una valoración extrema de la uniformidad cultural. Tanto en la literatura académica como en los debates públicos, estos riesgos parecen estar siempre asociados, bien a algún tipo de nacionalismo xenófobo, bien a algún tipo de fundamentalismo religioso. De aquí que tenga gran interés conocer las relaciones que, en el ámbito de la opinión pública europea, puedan establecerse entre diversos posicionamientos ideológicos de la población y su grado de multiculturalismo o de monoculturalismo. En concreto, estamos interesados en verificar hasta qué punto un alto grado de religiosidad está asociado con la adscripción a valores monoculturales. Con el objeto de establecer un adecuado contraste con otras importantes variables culturales, así como también de poder controlar la asociación manteniendo constantes otros posicionamientos, hemos incluido en el análisis las variables de ideología política y de nivel educativo. Inicialmente, analizamos las asociaciones bivariables y, en un momento posterior, presentaremos los resultados del análisis multivarible. 

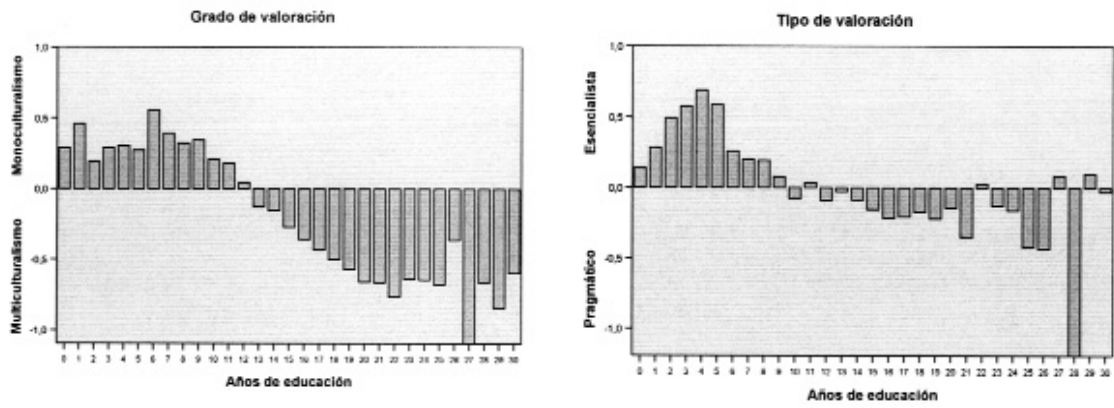

Gráfico 3c. Grado y tipo de valoración de la uniformidad cultural, según años de educación formal. Fuente: ESS, 2002. Elaboración propia.

Según los datos del gráfico 3.a., podemos constatar que existe una relación positiva entre grado de religiosidad y grado de monoculturalidad. Los europeos que se ubican en el extremo laico de la escala (posiciones 0,1 y 2) están orientados hacia la multiculturalidad, mientras que los ubicados en el extremo religioso, sobre todo los ubicados en la posición más extrema, alcanzan un elevado grado de monoculturalidad. Con respecto a su concepción cultural, los laicos resultan ser más pragmáticos, mientras que los religiosos son más esencialistas. Cabe resaltar que los laicos ubicados en la posición extrema muestran un elevado grado de pragmatismo.

Según los resultados del grafico 3.b., existe una relación positiva entre el posicionamiento ideológico de derechas y el grado de monoculturalismo. Puede destacarse el hecho de que los más izquierdistas, posición 0 de la escala, no son los más multiculturales, sino quienes se ubican en la posición 2 . En el ámbito de la derecha, la relación sí es continua, es decir, cuanto más derechista, más monocultural. Por lo que respecta a la concepción de la cultura, observamos que la relación, aunque intensa, sólo se produce en casos muy particulares. Los izquierdistas más extremos son excepcionalmente pragmáticos, mientras que los «apolíticos» son muy esencialistas.

Según los datos del gráfico 3.c, existe relación positiva entre el nivel educativo de las personas y su grado de multiculturalismo ${ }^{3}$. Esta relación general no es continua, pues presenta pautas diferentes en los diferentes tramos según los años de educación. Hasta los diez años de estudio, el grado de monoculturalismo es prácticamente constante; entre los diez y los veinte años, el grado de multiculturalismo crece con cada año de estudio adicional; a los veinte años, el grado de multiculturalismo alcanza su máximo, pero a partir de ahí permanece constante. Con respecto a la concepción de la cultura, se observa que quie-

3. Introducimos esta variable en el análisis por cuanto, sin ser una variable estrictamente ideológica, es, sin duda, una variable cultural, ya que el proceso educativo constituye un proceso fundamental de socialización mediante el que se introyectan valores sociales. 
nes no han cursado al menos diez años de estudios son más esencialistas. A partir de los diez años, cambia levemente la tendencia, y alcanza su cota máxima cuando se han cursado veinte años de estudios.

Las relaciones bivariables analizadas hasta ahora entre religiosidad, ideología política, nivel educativo y grado de monoculturalidad nos han informado en qué medida los europeos laicos o religiosos, de izquierdas o de derechas, y de bajo o de alto nivel educativo se adscriben a valores monoculturales o multiculturales, $y$ en qué medida conciben la cultura en términos pragmáticos o esencialistas. Ahora bien, en el marco de un trabajo de sociología cultural, adquiere la máxima importancia tratar de revelar las afinidades culturales que, en el sentido weberiano del término afinidad, mantengan las diversas ideologías con los valores monoculturales o multiculturales. Esta afinidad ideológica no puede captarse mediante los análisis bivariables precedentes, porque tan sólo muestran correlaciones brutas que, en parte, pueden ser debidas al efecto de terceras variables. Dicho de otra manera, no podemos saber si, por poner algún ejemplo, los religiosos son más monoculturales debido a que su nivel educativo medio es menor, o si los laicos son más multiculturales, no por el hecho de ser laicos, sino debido a que los laicos son más de izquierdas. En suma, lo que nos interesa conocer es si el «laicismo», en tanto complejo ideológico-cultural, resulta ser más afín a la multiculturalidad que el «izquierdismo» o el hecho de haber recibido más años de educación formal. En términos estadístico, esta afinidad cultural puede ser explorada aplicando análisis multivaribles que midan el efecto de cada una de las variables independientes sobre la dependiente, habiendo controlando o mantenido constante el resto de variables independientes. Por ejemplo, el efecto que tiene ser religioso o ser laico, independientemente del nivel educativo que unos y otros tengan, e independientemente de lo izquierdistas o derechistas que éstos sean.

Dado que buscamos relaciones entre posiciones culturales, hemos optado por aplicar una técnica logarítmica de dependencia, apta para variables categóricas o cualitativas, conocida como logit. La estrategia de contraste seguida para la estimación de los parámetros, que miden el efecto de cada posición ideológica en el grado de monoculturalismo o de multiculturalismo, ha consistido en comparar cada una de las dos posiciones ideológicas extremas (valores $0,1,2$ y valores 8,9 y 10 de la escala) con las posiciones ideológicas centrales (valores 3, 4, 5, 6 y 7). En suma, los parámetros del modelo logit saturado que se incluyen en el cuadro 5 nos indican hasta qué punto es más o menos probable pertenecer al tipo «muy monocultural» o al tipo «muy multicultural», cuando se es «izquierdista» o «derechista», en comparación con la probabilidad de quienes ocupan la parte central de esta escala ideológica. Idéntica estrategia se aplica a las otras dos variables independientes ${ }^{4}$.

4. La estrategia de estimación de los parámetros basada en el contraste entre posiciones ideológicas extremas se justifica sociológicamente, porque, en primer lugar, estos individuos suelen tener un mayor protagonismo, tanto en los debates culturales como en los conflictos sociales vinculados con ellos. En segundo lugar, porque suponemos que la afinidad ideológica se manifestará de modo más evidente en estas posiciones ideológicas extremas. 
Cuadro 5. Modelo logit: estimación de parámetros

\begin{tabular}{|c|c|c|c|}
\hline $\begin{array}{l}\text { Posiciones } \\
\text { culturales }\end{array}$ & $\begin{array}{c}\text { Muy } \\
\text { monocultural }\end{array}$ & $\begin{array}{c}\text { Muy } \\
\text { multicultural }\end{array}$ & $\begin{array}{l}\text { Monocultural } \\
\text { esencialista }\end{array}$ \\
\hline Laico & $-0,095$ & 0,548 & $-0,557$ \\
\hline Religioso & 0,330 & $-0,002$ & 0,334 \\
\hline Izquierda & $-0,210$ & 0,521 & $-0,043$ \\
\hline Derecha & 0,843 & $-0,564$ & 0,343 \\
\hline Esudios universitarios & $-0,949$ & 1,121 & $-0,314$ \\
\hline Estudios primarios & 0,270 & $-0,844$ & 0,604 \\
\hline Laico de izquierdas & $-0,388$ & 0,133 & $-0,314$ \\
\hline Laico de derechas & 0,362 & $-0,413$ & 0,076 \\
\hline Religioso de izquierdas & $-0,240$ & 0,561 & $-0,055$ \\
\hline Religioso de derechas & $-0,313$ & $-0,157$ & $-0,108$ \\
\hline Laico con estudios universitarios & $-0,008$ & $-0,224$ & $-0,165$ \\
\hline Laico con estudios primarios & 0,301 & 0,215 & $-0,375$ \\
\hline Religioso con estudios universitarios & 0,138 & $-0,148$ & 0,001 \\
\hline Religioso con estudios primarios & 0,229 & $-0,276$ & 0,020 \\
\hline Izquierda con estudios universitarios & s $-1,696$ & 0,514 & $-0,798$ \\
\hline Izquierda con estudios primarios & $-0,004$ & $-0,034$ & $-0,108$ \\
\hline Derecha con estudios universitarios & 0,504 & $-0,573$ & 0,492 \\
\hline Derecha con estudios primarios & 0,134 & $-0,063$ & $-0,158$ \\
\hline $\begin{array}{l}\text { Laico de izquierda } \\
\text { con estudios universitarios }\end{array}$ & 1,647 & $-0,246$ & $-0,037$ \\
\hline $\begin{array}{l}\text { Laico de izquierda con estudios } \\
\text { primarios }\end{array}$ & 0,801 & 0,328 & 0,738 \\
\hline $\begin{array}{l}\text { Laico de derecha } \\
\text { con estudios universitarios }\end{array}$ & $-0,180$ & 0,122 & $-0,322$ \\
\hline $\begin{array}{l}\text { Laico de derecha con estudios } \\
\text { primarios }\end{array}$ & $-0,273$ & 0,552 & 0,396 \\
\hline $\begin{array}{l}\text { Religioso de izquierda } \\
\text { con estudios universitarios }\end{array}$ & 0,368 & $-0,125$ & $-1,230$ \\
\hline $\begin{array}{l}\text { Religioso de izquierda } \\
\text { con estudios primarios }\end{array}$ & 0,676 & $-0,034$ & $-0,201$ \\
\hline $\begin{array}{l}\text { Religioso de derecha } \\
\text { con estudios universitarios }\end{array}$ & $-0,112$ & 0,278 & 0,135 \\
\hline $\begin{array}{l}\text { Religioso de derecha } \\
\text { con estudios pimarios }\end{array}$ & $-0,236$ & 0,425 & 0,148 \\
\hline
\end{tabular}

Fuente: ESS, 2002. Elaboración propia.

Sin abundar más en las características de esta técnica multivariable ${ }^{5}$, expondremos sucintamente las principales conclusiones que pueden derivarse de la estimación de los parámetros univariables, es decir, los incluidos en las seis pri-

5. Una de las virtudes de los modelos logit es que no estiman sólo los parámetros univariables, sino que también calculan los efectos que se producen por la interacción de categorías pertenecientes a dos o más variables. En el cuadro 5 también se muestran estos parámetros. 
meras filas del cuadro 5. Considerando los efectos netos univariables de cada uno de los posicionamientos ideológicos sobre el hecho de pertenecer al tipo «muy monocultural», que son, desde la perspectiva del multiculturarismo del miedo, los de mayor interés sociológico, comprobamos que la ideología política de derechas muestra la mayor afinidad con la defensa extrema de la uniformidad cultural $(0,843)$. Este efecto o afinidad es muy superior al del posicionamiento ideológico religioso $(0,330)$, o incluso al posicionamiento ideológico vinculado a bajo nivel de estudios. En términos substantivos, y pensando especialmente desde la perspectiva del multiculturalismo del miedo, se impone una primera conclusión: los riesgos de conflicto que puedan derivarse de la adhesión extrema a principios de uniformidad cultural aplicables en el interior de los paises europeos, procederán, en mucha mayor medida, de la dinámica politica y del apoyo popular que obtengan las posiciones politicas "derechistas", y no tanto de la dinámica de los sentimientos religiosos que profesen los europeos, de los europeos que muestren altos grados de religiosidad. Una segunda conclusión, atendiendo al hecho de que poseer un alto nivel de estudios reduce muy intensamente la probabilidad de defender posiciones muy monoculturales $(-0,949)$, sería la siguiente: la socialización en valores vinculada a procesos de educación formal parece constituir el mejor antídoto contra la defensa de una monoculturalidad extrema, inadecuada para garantizar la cohesión social de una Europa multiétnica y multicultural. Observando los parámetros incluidos en la segunda columna del gráfico, podemos comprobar que es también la educación la que muestra tener un mayor efecto $(1,121)$ sobre la defensa extrema de la diversidad cultural, mucho mayor que el hecho de ser «laicista» $(0,548)$, o que el hecho de ser «izquierdista» $(0,521)$.

El análisis minucioso de los efectos de interacción, tanto bivariables como trivariables, contenidos en el cuadro 5 permite desarrollar el análisis de las afinidades culturales cuando se combinan posicionamientos ideológicos diversos. Los efectos univariables son los que corresponden al mero hecho de ser, por ejemplo, «laicista», «izquierdista» o «universitario», pero no nos indican qué efecto tiene el hecho de ser las tres cosas a la vez, es decir, un «laico, de izquierdas, con formación universitaria». Pues bien, si observamos el valor de este parámetro de interacción en el cuadro 5, comprobaremos que, contra lo que podría esperarse, no tiene el efecto de reducir el monoculturalismo o aumentar el multiculturalismo, sino todo lo contrario. El hecho de ser «laicista, izquierdista y tener estudios universitarios» tiene el efecto de incrementar en mucho el grado de monoculturalismo $(1,647)$, e incluso de reducir en algo el grado de multiculturalismo $(-0,246)$. La explicación a este resultado contraintuitivo podemos encontrarla en la afinidad ideológica de las personas que compartan estas tres características con el ethos cultural de la Ilustración, inspirada en una razón universalista, y con el ethos político de la Revolución Francesa, inspirada en un concepto de ciudadanía individualista, en el que no caben identidades étnicas o culturales que puedan segmentar colectivamente la población de un estado. Estas personas suelen defender un tipo especial de monoculturalismo universalista y muy pragmático, desde el que resulta inconcebible e incomprensible 
el sentido que puedan tener las formas y las fórmulas, tanto comunitarias como identitarias, en las que se expresan las comunidades étnicas o culturales.

No podemos abordar aquí el análisis completo de las interesantes afinidades culturales e ideológicas que ponen de relieve los numerosos efectos de interacción incluidos en el cuadro 5. Tan sólo queremos insistir en que, tanto sociológica como culturalmente, las interacciones se corresponden con tipos de posicionamientos ideológicos mucho más reales que los que puedan establecerse mediante las categorías de una única variable. No somos tan sólo de izquierdas o de derechas, sino que también somos, simultáneamente, religiosos o laicos. Y el hecho de ser una "persona religiosa de izquierdas» o ser una «persona religiosa de derechas", constituye en sí mismo una posición ideológica particular cargada de afinidades culturales específicas. De ahí el interés que, para un análisis de sociología cultural, posee el cálculo de estos efectos de interacción.

\section{El multiculturalismo como respuesta moral al reto de la multiculturalidad}

Hemos comenzado el artículo señalando que Europa está conformada por un conjunto de sociedades étnica y culturalmente muy diversas, esto es, afirmando que la multiculturalidad de Europa constituye hoy un hecho insoslayable. Ahora bien, a juzgar por toda la información empírica analizada en este trabajo, podríamos también afirmar, con idéntico convencimiento, que el multiculturalismo, esto es, la genuina valoración de la diversidad étnica y cultural, constituye todavía hoy un reto, un incipiente proyecto moral que debería nutrir íntimamente en el próximo futuro el modo de ser europeo. Los datos no dejan lugar a dudas. Incluso los europeos que, en el marco de la tipología elaborada, hemos catalogado estadísticamente como «multiculturales» presentan un perfil de respuestas alimentado por un indiscutible deseo y una valoración de la uniformidad cultural (cuadro 4). Así pues, desde una interpretación sociológica de carácter normativo, es preciso resaltar el hecho de que tan sólo el $17,3 \%$ de la población europea manifiesta tener unas convicciones genuinamente multiculturales. Estos europeos, a los que hemos catalogado estadísticamente como «muy multiculturales», son los únicos que parecen estar coherentemente implicados con la defensa de la diversidad cultural.

Estos resultados no deberían sorprendernos demasiado. Si pensamos, tal y como sostiene O'Neil, que, en la historia de la filosofía occidental, la diversidad no ha sido objeto de especial atención, y que siempre se ha enfatizado el valor de la homogeneidad, del consenso y de la comunidad, así como la relevancia de las asunciones comúnmente aceptadas y de los vínculos que mantienen a una sociedad unida (O'Neil, 2002), no ha de extrañarnos que sigamos pensando que la uniformidad cultural constituye una base imprescindible para el logro del orden social. Esto es, precisamente, lo que en el fondo seguimos pensando los europeos.

Ahora bien, estamos convencidos de que la superación de este profundo y auténtico sentimiento monoculturalista, que anima nuestras más íntimas acti- 
tudes, no puede cerrarse en falso recurriendo a meras declaraciones públicas, hoy en boga, sin duda políticamente correctas, en defensa del multiculturalismo y de la diversidad étnica y cultural. Creemos que resulta imprescindible la promoción de un verdadero debate público, descargado de toda hipocresía, en el que todos se expresen libre y sinceramente, contrastando sus ideas respectivas, argumentando sobre sus valores y exponiendo sus propias emociones. Sólo mediante un debate público de este tipo seremos perfectamente conscientes de cuál es nuestra verdadera posición con respecto al multiculturalismo. Sólo así podremos discutir y seremos capaces de superar el reto. Nada hay más engañoso que la aparente sencillez de los argumentos asociados con la simple «defensa» o «rechazo» de la diversidad cultural. Todos los discursos sociales en liza esconden una gran complejidad preñada de múltiples paradojas y contradicciones.

En suma, creemos que la definición precisa de cada posicionamiento sólo puede entenderse si se comprenden las claves ideológicas que subyacen a cada uno de los discursos que alimentan este debate público (liberalismo vs. comunitarismo; etnocentrismo vs. pluricentrismo; ámbito público vs. ámbito privado); también si se comprende la concepción o idea de cultura de la que se parte (esencialismo vs. pragmatismo), y si se comprende, en tercer lugar, la doble dialéctica que afecta a estos discursos (nosotros vs. ellos; mayoría vs. minoría). Éste es, precisamente, el conjunto de claves que configuran y permiten comprender el contenido de los posicionamientos morales que inspiran los discursos en torno a la defensa de la uniformidad o de la diversidad cultural. Por supuesto, también establecen importantes matices a la hora de determinar el contenido cultural y moral de los cuatro elementos de nuestra tipología: el monoculturalismo esencialista, el monoculturalismo pragmático, el multiculralismo pragmático y el multiculturalismo esencialista. Dada su gran trascendencia, expondremos sucintamente la relación de cada una de estas claves con la valoración de la uniformidad o de la diversidad sociocultural.

Liberalismo: la posición liberal clásica tiene un marcado carácter individualista, desde el que no se otorga ningún sentido ni a las comunidades culturales ni a las identidades colectivas. El concepto de ciudadanía ordena el vínculo político fundamental, vínculo que se establece exclusivamente entre cada individuo y el estado. La posición liberal se sustenta sobre un «individualismo abstracto» (Lamo de Espinosa, 1995b: 42), y de ahí que el liberalismo sea proclive a la defensa de la diversidad en términos puramente personales, pero recele de la diversidad cuando adquiere tintes grupales, comunitarios o identitarios. Su modelo ideal de multiculturalismo se corresponde con un cosmopolitismo individualista en el que cada ser humano es libre para adoptar, asimilar o hibridar cuantos rasgos crea convenientes del muestrario completo que ofrece la diversidad cultural de la humanidad.

Comunitarismo: desde una posición ideológica comunitarista, se entiende que la pertenencia a un grupo constituye la forma natural de la sociabilidad humana. Dicho de otro modo, se entiende que un individuo sólo puede lle- 
gar a ser tal cuando está integrado en una cultura y en una comunidad. Así, el multiculturalismo comunitario defiende la coexistencia y la convivencia de diversas comunidades culturales. La paradoja, señalada entre otros por Levy, es que esta defensa de comunidades culturales requiere que tales comunidades existan y, por tanto, exige la defensa de la homogeneidad cultural en el seno de las mismas (Levy, 2000: 145). En este contexto, se puede ser al mismo tiempo defensor de valores multiculturalistas en el ámbito general de la sociedad y, al mismo tiempo, defensor de valores monoculturalistas en el ámbito particular de cada comunidad.

Etnocentrismo: el etnocentrismo, en la medida que valora la cultura de la sociedad o de la comunidad de pertenencia como superior a las otras culturas, establece, en el mejor de los casos, un principio de mera tolerancia multicultural, cuando no de franco desprecio hacia el resto de las culturas. La tesis de la superioridad de una cultura, bien sea defendida en términos universalistas («Mi cultura es la forma superior de la cultura de la humanidad»), bien se la defienda en términos particularistas («Mi cultura es superior por sus rasgos particulares»), conduce directamente, desde el absolutismo moral que proclama, a políticas de asimilación e integración cultural. Ahora bien, aunque desde un universalismo moral puedan llegar a establecerse algunos criterios generales para la valoración de las culturas, conviene no olvidar que si bien una cultura podría ser considerada superior a otra, nunca podríamos determinar la superioridad de un ser humano sobre otro. Y este hecho determina un límite moral del etnocentrismo.

Pluricentrismo: la creencia de que todas y cada una de las culturas tienen un valor propio está íntimamente asociada con la valoración de la diversidad cultural y con un interés en la preservación de las culturas. La dignidad que pueda atribuirse a toda cultura, por el mero hecho de ser la expresión de vida de un colectivo de seres humanos, puede entenderse, al estilo de Montesquieu, en tanto respeto y comprensión al resultado particular que emerge de la aplicación de un mismo principio universal a la múltiple diversidad de condiciones de existencia a la que se enfrentan los seres humanos. También puede ser entendida, siguiendo la estela de Herder, en términos de los principios valiosos que cada cultura específica realiza en la práctica. El pluralismo moral implica que los valores activados o realizados por las diversas culturas son hasta cierto punto incomparables, inconmensurables e incompatibles entre sí. La defensa extrema del pluralismo puede abocar en un puro relativismo moral en el que no tendría sentido el ejercicio de la crítica cultural.

Ámbito privado: la aceptación de la diversidad cultural siempre que quede contenida en el ámbito de la realidad íntima o privada de los individuos, o en el ámbito que nutre la limitada sociabilidad de los grupos primarios, sean familiares, étnicos, religiosos o asociativos, no plantea problemas especiales a la integración política nacional. Se defiende un multiculturalismo folclórico o culturalista cuando se acepta la diversidad en términos de cultura, pero se niegan las implicaciones políticas de los agrupamientos sociales establecidos median- 
te identidades culturales, étnicas, religiosas o comunitarias. La estricta separación de los ámbitos privado y público constituye el principio que inspira, en este tipo de posicionamientos, el respeto a la diversidad cultural.

Ámbito público: el problema se plantea de forma muy diferente cuando la identidad de las diversas comunidades culturales puede afectar, o de hecho afecta, al ámbito público. Cuando esto sucede, la multiculturalidad trasciende el estricto ámbito de la "cultura», introduciéndose por derecho propio en el ámbito de la «política». En primer lugar, las identidades culturales comienzan a desempeñar un papel en los juegos de poder. En segundo lugar, se cuestiona la identidad de la cultura nacional y se requieren nuevas respuestas a las viejas preguntas: quiénes somos y cómo queremos convivir (Berger, 1999). En tercer lugar, no cabe la mera admisión cosmética de la diversidad, ni tampoco la mera tolerancia o el simple respeto (Taylor, 1993). En este caso, el estado debe reconocer públicamente el valor de las diversas comunidades culturales que pueblan su territorio, por lo que las meras políticas de redistribución, o el mero combate contra la intolerancia y la exclusión son insuficientes. El estado debe establecer adecuadas politicas de reconocimiento, otorgando dignidad, mecanismos de voz y reconocimiento público a los grupos y a las comunidades culturales, al mismo tiempo que debe mantener un sentido general de identidad nacional (Raj, 2006).

Concepción cultural esencialista: la existencia de un centro de gravedad específico en la cultura particular y única de cada pueblo nos remite a una esencia o substancia cultural conformada intersubjetivamente a través de la historia y que, por tanto, ha de tener su referencia primordial en el pasado, en las costumbres y en las tradiciones de cada pueblo. La concepción esencialista se corresponde con la moderna idea objetiva de cultura, frente a lo que sería una idea subjetiva o subjetual de la misma (Bueno, 1996). Se corresponde con el concepto de cultura en tanto opuesto al de civilización (Lamo de Espinosa, 1995b). «Ningún individuo se ha hecho hombre por sí mismo, dice Herder, por tanto, todos los hombres se forman gracias a la "generación espiritual" que llamamos educación» (Bueno,1996: 58). Lamo de Espinosa sintetiza las diferencias señalando que «el contraste entre Montesquieu y Herder, como el contraste entre civilización y cultura, tiene, pues, múltiples dimensiones: el rechazo o la sublimación de las tradiciones; los derechos individuales vs. los derechos colectivos; una orientación al futuro o hacia el pasado; la tensión entre uniformización y respeto a la diversidad» (Lamo de Espinosa, 1995: 40).

Concepción cultural pragmática: la existencia en el individuo de un mecanismo universal, la razón naturaleza, mediante la que los seres humanos se adaptan a las circunstancias específicas con las que tienen que enfrentarse en la vida, alude a la circunstancialidad última de cada constelación cultural, en la que no existe esencia alguna, sino más bien proyecto pragmático de desarrollo orientado desde la condición presente hacia el futuro. Para Gustavo Bueno, la idea subjetual de cultura es muy antigua y está relacionada con la paideia griega, que remite al proceso de cultivo y de aprendizaje que logra tanto 
transformar la «naturaleza» originaria de un individuo, como alterar su «herencia». Mediante este proceso, el individuo adquiere cultura y se convierte en una persona "culta». La conciencia y la valoración de la diversidad cultural implícitas en la obra de Montesquieu, insertas en el marco de una razón naturaleza que opera pragmáticamente según las circunstancias, no entra en contradicción con el proyecto civilizador y universalista de la Ilustración francesa. "Las costumbres de otros pueblos pueden ser contrarias a las nuestras, pero esto no significa que sean contrarias a la razón, pues la naturaleza de los hombres es la misma aunque se exprese en costumbres diferentes o incluso opuestas, debido, en parte, a las diferentes condiciones en que los seres humanos tienen que desarrollar su vida» (Lamo de Espinosa, 1995: 37).

En último término, aunque sin duda no el menos importante, debemos comentar la dialéctica social que establece el doble contraste entre nosotros/ellos y entre mayoríalminoría a la hora de definir el posicionamiento de cada individuo frente al reto de la multiculturalidad, dialéctica que todavía hace más complejo y paradójico el campo de los discursos morales. Muchos individuos aplican a su propia cultura unos principios que en ningún caso aplicarían a una cultura ajena. Así, pueden defender la homogeneidad de la esencia cultural propia sosteniendo al mismo tiempo la destrucción de la esencia cultural ajena. Muchos individuos se adscriben a unos o a otros valores dependiendo de si forman parte de una mayoría o de una minoría. Así, pueden defender el multiculturalismo en el ámbito nacional y estar aplicando un férreo monoculturalismo en el ámbito particular de su comunidad cultural. Ahora bien, ha de considerarse con toda seriedad el hecho de que un discurso asimétrico nunca puede llegar a ser un verdadero discurso moral.

El multiculturalismo, considerado como respuesta moral al reto de la multiculturalidad, debería resolver también otro dilema básico. Aquél que se cierne entre una valoración meramente pragmática y una valoración puramente esencialista de la diversidad cultural. Unas comunidades culturales extremadamente cerradas, que exijan un reconocimiento público en tanto tales, que impidan la coalescencia social y cultural de sus miembros, que preserven contra viento y marea los rasgos esenciales de su cultura, y que se orienten en exclusiva hacia el pasado y hacia la tradición, serán capaces de mantener el orden de la cultura, pero serán incapaces de establecer los cauces por los que fluya un auténtico diálogo intercultural. A la inversa, una valoración exclusivamente pragmática de la diversidad, una cultura perfectamente individualizada sin apenas sustento grupal, o totalmente abierta y descompuesta en un conjunto inconexo de rasgos, nos conduciría a un profundo proceso de vaciado cultural y, por ende, a un fútil diálogo intercultural, convertido así en mera cháchara. Entre la versión más desleída de multiculturalismo pragmático, es decir, entre el cosmopolitismo banal, y el más extremo y cerrado multiculturalismo esencialista o comunitario, deberíamos encontrar posiciones morales intermedias desde las que establecer un auténtico y profundo respeto por los seres humanos. 
Kant nos recuerda que todo ser humano constituye un fin en sí mismo, nunca un medio. Así que, en cualquier caso, y sea cual sea nuestra posición en el debate, lo más importante es que nunca olvidemos tratar a un ser humano como un ser humano. Esta sencilla regla es fundamental.

\section{Bibliografía}

AleXANDER, J. (2001). "Theorizing the Modes of Incorporation». Sociological Theory, núm. 19(3), p. 237-249.

AlsAYYAD, N.; CASTELls, M. (eds.) (2002). ¿Europa musulmana o Euro-Islam?: Política, cultura y ciudadanía en la era de la globalización. Madrid: Alianza.

Amin, A. (2004). «Multi-ethnicity and the Idea of Europe». Theory, Culture and Society, vol. 21(2), p. 1-24.

BARrY, B. (2001). Culture and equality. Cambridge: Polity Press.

BECK, U. (2002). "The Cosmopolitan Society and its Enemies». Theory, Cultura \& Society, núm. 19 (1-2), p. 17-44.

BERGER, P. L. (ed.) (1999). Los limites de la cohesión social. Conflicto y mediación en las sociedades pluralistas: Informe de la Fundación Bertelsmann al Club de Roma. Barcelona: Galaxia Gutemberg.

BERICAT, E. (dir.) (2003). El conflicto cultural en España: Acuerdos y desacuerdos entre los españoles. Madrid: CIS.

BericAT, E. y PINO, A. del (1998). Valores sociales en la cultura andaluza. Madrid: CIS. BERLIN, I. (1976). Vico and Herder: Two Studies in the History of Ideas. Londres: The Hogarth Press.

BuenO, G. (1996). El mito de la cultura. Barcelona: Prensa Ibérica.

CEA D’ANCONA (2004). La activación de la xenofobia en España. ¿Qué miden las encuestas? Madrid: CIS.

Entzinger, H. (2003). «The rise and Fall of Multiculturalism: The case of the Netherlands». En: JOPPKE, C. y MORAWSKA, E. (eds.). Toward assimilation and citizenship. Basingstoke: Palgrave Macmillan.

GINER, S. y SCARTEZZINI (eds.) (1996). Universalidad y diferencia. Madrid: Alianza. Habermas, J. (2006). Entre naturalismo y religión. Barcelona: Paidós.

Hall, S. y Du GaY, P. (comps.) (2003). Cuestiones de identidad cultural. Buenos Aires: Amorrortu.

HARTMANN, D. y GerTeIS, J. (2005). «Dealing with Diversity: Mapping Multiculturalism in Sociological Terms». Sociological Theory, núm. 23(2), p. 218-240.

IsAR, Y. R. (2006). "Cultural Diversity». Theory, Culture and Society, vol. 23(2-3), p. 372-375.

JAHANBEglOO, R. (2007). Elogio de la diversidad. Barcelona: Arcadia.

JOPPKE, C. (2007). «State neutrality and Islamic headscarf laws in France and Germany». Theory and Society, vol. 36, núm. 4, p. 313-342.

- (2004). "The retreat of multiculturalism in the liberal state: theory and policy». The British Journal of Sociology, vol. 55, 2, p. 237-257.

JOPPKE, C. y LUKES, S. (1999). Multicultural questions. Oxford: Oxford University Press.

KyMlicKA, W. (1995): Multicultural citizenship. Oxford: Oxford University Press. KymLicKa, W. y Norman, W. (2001). Citizenship in diverse societies. Oxford: Oxford University Press. 
LAMO DE EsPINOSA, E. (ed.) (1995a). Culturas, estados, ciudadanos: Una aproximación al multiculturalismo en Europa. Madrid: Alianza.

- (1995b). «Fronteras culturales». En: Culturas, estados, ciudadanos: Una aproximación al multiculturalismo en Europa. Madrid: Alianza.

- (1996). Sociedades de cultura, sociedades de ciencia: Ensayos sobre la condición moderna. Oviedo: Nobel.

LEVY, J. T. (2000). El multiculturalismo del miedo. Madrid: Tecnos.

MeluCCI, A. (1997). «Identity and Difference in a Globalized World». En: ModOoD, T. y WeBNER, P. (eds.). The politics of multiculturalism. Londres: Zed.

Lamont, M. y Molnár, V. (2002). "The Study of Social Boundaries in the Social Sciencies». Annual Review of Sociology, núm. 28, p. 167-195.

O’NeIL, D. J. (2002). «Caveats concerning multi-culturalism». International Journal of Social Economics, vol. 29, núm. 3, p. 238-250.

PareKhn, B. (2000). Rethinking multiculturalism. Basingstoke: Palgrave Macmillan.

Raj Isar, Y. (2006). «Cultural Diversity». Theory, Culture \& Society, núm. 23 (2-3), p. 372-375.

REX, J. (1995). «La metrópoli multicultural: La experiencia británica». En: LAMO DE ESPINOSA, E. (ed.). Culturas, estados, ciudadanos: Una aproximación al multiculturalismo en Europa. Madrid: Alianza.

SHWEDER, R. A.; MinOw, M. y MARKUS, H. R. (eds.) (2002). Engaging cultural differences: The multicultural challenge in liberal democracies. Nueva York: Russell Sage Foundation.

SORA (Thalhammer, E.; Enzenhofer, E.; Salfinger, B. y Ogris, G.) (2001). Attitudes towards minority groups in the European Union: A special analysis of the Eurobarometer 2000 survey. Viena: European Monitoring Centre of Racism and Xenophobia.

STOLCKE, V. (1995). «Talking culture: New Boundaries, New Rhetorics of Exclusion in Europe». Current Anthropology, vol. 36, núm. 1, p. 1-24.

TAYLOR, Ch. (1993). "Multiculturalism and the "Politics of Recognitions"». En: Gutmann, Amy (ed.). Multiculturalism and the "Politics of Recognitions". Princeton: Princeton University Press.

Young, I. M. (2000). Inclusion and democracy. Oxford: Oxford University Press. 